\title{
REVISÃO DO GÊNERO NEOTROPICAL Acanthocera MACQUART (DIPTERA: TABANIDAE).
}

\author{
Augusto Loureiro HENRIQUES ${ }^{1}$, José Albertino RAFAEL ${ }^{2}$
}

\begin{abstract}
RESUMO - O gênero Acanthocera Macquart é redefinido e apresentado lista sinonímica, diagnose, figuras e chave para fêmeas das 28 espécies. O subgênero Nothocanthocera Fairchild do gênero Dichelacera é transferido para Acanthocera, exceto D. melanoptera Hine, e descrita uma espécie: $A$. distincta, sp. n. O subgênero Mimodynerus Enderlein é sinonimizado sob $A$. (Acanthocera). A bequaerti Fairchild \& Aitken é revalidada. A. lutzi (Enderlein) é sinonimizada sob A. coarctata (Wiedemann). A fêmea de A. polistiformis Fairchild é descrita. Um novo lectótipo é designado para A. tenuicornis.
\end{abstract}

Palavras-chave:Acanthocera, Diptera, Neotrópicos, Tabanidae, Taxonomia.

Revision of the Neotropical genus Acanthocera MacQuart (Diptera:Tabanidae)

ABSTRACT - The Neotropical genus Acanthocera Macquart is redefined. 28 species are presented with synonymic list, figures, diagnosis and key to females. The subgenus Nothocanthocera Fairchild of Dichelacera is transferred to Acanthocera, except for D. melanoptera Hine and one species is described: A. distincta, n. sp. The subgenus Mimodynerus Enderlein is synonymized with Acanthocera. A. bequaerti Fairchild \& Aitken is revalidated. A. lutzi (Enderlein) is synonymized with $A$. coarctata (Wiedemann). The female of polistiformis Fairchild is described. A new lectotype is designated for A. tenuicornis.

Key words: Acanthocera, Diptera, Neotropics, Tabanidae, Taxonomy.

\section{INTRODUÇÃO}

Espécimes de Acanthocera não são observados com facilidade, pois a maioria habita o dossel da floresta e são mais frequentemente coletados com armadilha suspensa, descrita por RAFAEL \& GORAYEB (1982). Em virtude deste comportamento algumas espécies estão pouco representadas nas coleções do mundo. É provável que na procura do repasto sanguíneo as fêmeas ataquem aves e pequenos mamíferos que habitam o estrato superior da floresta, tais como mutum, preguiças, macacos e cuatis. Os estágios imaturos são desconhecidos e pode-se apenas supor que algumas espécies ocorram em coleções de água nas bainhas de bromélias epifíticas.

\section{HISTÓRICO}

O gênero Acanthocera foi proposto por MACQUART em 1834 para Tabanus longicornis Fabricius, 1775. Macquart provavelmente não viu a espécie e talvez tenha se baseado em

1 Museu Paraense Emílio Goeldi, Departamento de Zoologia, Caixa Postal 399, 66017-970, Belém, PA, Brasil. Bolsista do CNPq.

2 Instituto Nacional de Pesquisas da Amazônia, Caixa Postal 478, 69011-970, Manaus, AM, Brasil. Bolsista do CNPq. 
material erroneamente determinado, pois no mesmo trabalho descreve Tabanus pictipennis e mais tarde (1838) Dichelacera longicornis, ambas sinônimos de Acanthocera longicornis (Fabricius). Na chave para os gêneros de Tabanidae, MACQUART (1838) coloca Acanthocera entre as mutucas destituídas de processo no flagelo, o que não é verdadeiro, pois a espécietipo possui um longo espinho no primeiro flagelômero. WALKER (1854) e SCHINER (1868) reconhecem o gênero e descrevem respectivamente as espécies $A$. marginalis e A. trigonifera, além de incluirem uma espécie de Wiedemann: Haematopota exstincta. RICARDO (1904) inclui outra espécie de Wiedemann no gênero: $H$. coarctata. LUTZ (1915) redefine o gênero e descreve mais seis espécies: $A$. anacantha, $A$. eristalis, $A$. intermedia, A. nigricorpus, $A$. quinquecincta e $A$. tenuicornis. ENDERLEIN (1922, 1925) na revisão da família Tabanidae, divide o gênero em duas tribos e quatro gêneros na subfamília Diachlorinae, com base na presença de espinho antenal e constrição no abdômen: Spheciogaster Enderlein e Acanthocera em Acanthocerini e Mimodynerus Enderlein e Lutziella Enderlein em Diachlorini, e descreve a espécie Spheciogaster lutzi. KROEBER (1928, 1930, 1934) mantém esta classificação, com exceção do gênero Mimodynerus sinonimizado sob Spheciogaster e descreve as espécies A. formosa e Spheciogaster albomarginatus. FAIRCHILD (1939) na revisão do gênero Acanthocera, não considera os caracteres de Enderlein
(1922, 1925) suficientes para o estabelecimento dos gêneros, redefine o gênero Acanthocera colocando Spheciogaster e Lutziella sob sua sinonímia e descreve mais três espécies: A. apicalis, A. blaseri e A. kroeberi. Mais tarde, FAIRCHILD (1941) descreve A. costaricana. BARRETTO (1947) aceita a definição de Fairchild e adiciona mais cinco espécies: $A$. cnephosa, A. diaphorina, $A$. leucotibialis, A. steleiothorax e A. vespoides. FAIRCHILD \& AITKEN (1960) descrevem $A$. bequaerti. FAIRCHILD (1961b) descreve $A$. polistiformis. Em seguida, FAIRCHILD (1969) propõe a divisão do gênero em três subgêneros: Acanthocera, Mimodynerus e Polistimima; e baseado no comprimento do escapo propõe o subgênero Nothocanthocera no gênero Dichelacera, para onde dez espécies do género Acanthocera são transferidas, a saber: A. albomarginata, A. apicalis. A. cnephosa, A. costaricana, A. diaphorina, A. leucotibialis, $A$. nigricorpus, A. steleiothorax, $A$. tenuicornis (Espécie-tipo) e $A$. trigonifera. FAIRCHILD (1971) em seu catálogo dos tabanídeos neotropicais, lista doze espécies válidas no gênero Acanthocera, com suas sinonímias e referências. WILKERSON (1981) reconhece o subgênero Nothocanthocera em Dichelacera e acrescenta mais duas espécies: $D$. adusta e D. flavicosta. HENRIQUES \& RAFAEL(1992) descrevem mais quatro espécies em $A$. (Acanthocera): A. aureoscutellata, A. bicinota, $A$. fairchildi e $A$. gorayebi. 


\section{MATERIAL E MÉTODOS}

Foram examinados 1083 exemplares, incluindo $80 \%$ dos tipos, material este obtido por empréstimo das seguintes instituições: American Museum of Natural History (AMNH) EUA; The Natural History Museum (BMNH) Inglaterra; California Academy of Sciences (CAS) EUA; Field Museum of Natural History (FMNH) EUA; Florida State Collection of Arthropods(FSCA)EUA; Zoologisches Institut, Martin Luther Universität (HALLE) Alemanha; Instituto Nacional de Pequisas da Amazônia (INPA) Brasil; Fundação Instituto Oswaldo Cruz (FIOC) Brasil; Museum of Comparative Zoology (MCZ) EUA; Museu Nacional da Universidade Federal do Rio de Janeiro (MNRJ) Brasil; Museu Paraense Emilio Goeldi (MPEG) Brasil; Museu de La Plata (MLP) Argentina; Museu de Zoologia da Universidade de São Paulo (MZUSP) Brasil; The Ohio State University (OSU) EUA; Universidade Federal do Paraná (UFPR) Brasil; National Museum of Natural History, Smithsonian Institution (USNM) EUA; Universitetets Zoologiske Museum (UZM) Dinamarca; Zoologisches Museum der Math.-Naturwissenchaftlichen Facultät der Humboldt Universität zu Berlin (ZMHU) Alemanha.

A terminologia morfológica adotada é a de McALPINE (1981), adaptada para o gênero Acanthocera (Fig. 1). A determinação do Índice Frontal é calculada pelo comprimento da fronte, desde o vértice até a sutura entre a fronte e o subcalo, dividido pela largura da fronte nesta sutura (FAIRCHILD, 1985: 301). Em Material Examinado, para não nos extendermos demasiadamente nos dados de etiquetas em longas séries, relacionamos o número de fêmeas e machos com os respectivos locais de depósito. Todos os espécimes, com data de determinação entre 1986 1992, estão com etiquetas de determinação, ora com o primeiro autor, ora com o segundo, o que facilita a identificação do material utilizado neste estudo.

\section{Gênero Acanthocera Macquart} Acanthocera MACQUART, 1834: 209; SCHINER, 1866: 95; KERTÉSZ, 1900: 29 (catálogo); HUNTER,1901:137 (catálogo);LUTZ, 1915: 52 (redefinição); ENDERLEIN, 1922: 349 (em chave); 1925: 333 (definição); BORGMEIER, 1933: 287; KROEBER, 1928: 84 (redefinição, chave); 1934:254 (catálogo); FAIRCHILD, 1939: 15 (revisão); BARRETTO, 1947: 89; 1960: 58 (em chave); FAIRCHILD, 1969: 208 (subgêneros); 1971: 58 (catálogo); COSCARÓN, 1978: 28. Espécie-Tipo Tabanus longicornis Fabricius (mon.).

Lutziella ENDERLEIN, 1922: 350 (em chave); 1925: 337 (definição); KROEBER, 1928: 94 (redefinição); 1934: 254 (catálogo); FAIRCHILD, 1939: 15 (como sinônimo de Acanthocera). Espécie-Tṕo Acanthocera eristalis Lutz (des. orig.). 
Mimodynerus ENDERLEIN, 1922: 350 (em chave); 1925: 337 (definição); KROEBER, 1934: 235 (como sinônimo de Spheciogaster). Espécie-Tipo Acanthocera anacantha Lutz \& Neiva (des. orig.).

Spheciogaster ENDERLEIN, 1922:

349 (em chave); 1925: 333 (definição); KROEBER, 1928:

80 (redefinição); 1934: 253 (catálogo); FAIRCHILD, 1939: 15 (como sinônimo de Acanthocera). Espécie-Tipo Spheciogaster lutzi Enderlein (des. orig.).

O gênero Acanthocera pode ser definido pelos seguintes caracteres: tamanho 9,0 - 17,7 mm; corpo delgado, semelhante a vespas (Hymenoptera: Vespidae); antena relativamente longa, podendo exceder o comprimento da tíbia posterior; flagelo maior que o escapo e pedicelo juntos, exceto $A$. polistiformis; primeiro flagelômero geralmente com espinho dorsal, ou protuberância, ou ainda liso; olhos glabros ou pilosos, na maioria das espécies com duas bandas horizontais e margem posterior verdes, o restante roxo; ocelos vestigiais ou ausentes; face um pouco inflada, brilhante com faixas de pruinosidade; labela parcialmente esclerotinizada; palpo maxilar geralmente delgado, entretanto pode apresentar-se bastante dilatado; presença de pruinosidade acinzentada ao redor dos olhos expandindo-se no occipício; tórax geralmente ormamentado com tufos de pêlos amarelo- dourados no lado e faixas de pruinosidade amarela no dorso; pernas geralmente bicoloridas; asa com basicosta nua e macrotríquias nas veias Costal, Subcostal e as primeiras Radiais; asa geralmente com enfuscação localizada na margem anterior e célula cup; abdômen longo com constrição ao nível do segundo e terceiro segmentos, geralmente com cintas de pêlos e pruinosidade amarelos, pelo menos nos dois primeiros tergitos; pruinosidade cinza-azulada nos dois primeiros tergitos em vista posterior e pruinosidade esbranquiçada no primeiro esternito.

Segue abaixo a lista das espécies de Acanthocera, em seus respectivos subgêneros.

Acanthocera (Acanthocera) Macquart anacantha Lutz \& Neiva

aureoscutellata Henriques \& Rafael *

bequaerti Fairchild \& Aitken bicincta Henriques \& Rafael * blaseri Fairchild coarctata (Wiedemann)

$=$ lutzi (Enderlein), sin.n.

= vespoides Barreto

eristalis Lutz

exstincta (Wiedemann)

fairchildi Henriques \& Rafael * formosa Kroeber $=$ marginalis Walker

gorayebi Henriques \& Rafael * intermedia Lutz

kroeberi Fairchild

longicornis (Fabricius) * $=$ triangularis (Wiedemann)

* Espécies com macho conhecido. 
= pictipennis Macquart

marginalis Walker *

quinquecincta Lutz

Acanthocera (Nothocanthocera)

(Fairchild)

adusta (Wilkerson), comb.n.

albomarginata (Kroeber),comb.n. apicalis Fairchild, comb.n. * cnephosa Barretto, comb.n. costaricana Fairchild, comb.n. diaphorina Barretto, comb.n. * = leucotibialis Barretto distincta sp. $\mathrm{n}$.

flavicosta (Wilkerson), comb.n. nigricorpus Lutz, comb.n. * steleiothorax Barretto, comb.n. * tenuicornis Lutz, comb.n. * trigonifera Schiner, comb.n.

Acanthocera (Polistimima) Fairchild polistiformis Fairchild *

\section{Chave para os subgêneros e espécies das fêmeas de} Acanthocera.

1 - Flagelo menor que escapo e pedicelo juntos; corpo amareloavermelhado;palpo extremamente inflado(Fig.28c)

(Polistimima) polistiformis

1a- Flagelo maior que escapo e pedicelo juntos, palpo variável..2

2 - Antena visivelmente maior que a tíbia posterior, se do mesmo tamanho, os três primeiros anuli são da mesma largura do primeiro flagelômero (Figs. 2a16a) ...... (Acanthocera) 3

2a- Antena visivelmente menor que a tíbia posterior, se do mesmo tamanho, o estilo é mais estreito que o primeiro flagelômero (Figs.

$17 \mathrm{a}-27 \mathrm{a})$

(Nothocanthocera) 17

3 - Espinho ou protuberância ausente no primeiro flagelômero ......... 4

3a- Espinho ou protuberância presente no primeiro flagelômero ......... 7

4 - Olhos glabros ......................... 5

4a- Olhos pilosos ........................... 6

5 - Palpo maxilar inflado (Fig. 2c); escutelo com pêlos pretos

anacantha

5a-Palpo normal (Fig. 12c), escutelo com pêlos dourados

intermedia

6 - Tergito 2 com banda posterior larga, amarelo-dourada

kroeberi

6a- Tergito 2 preto, exceto por alguns pêlos amarelos na borda posterior. quinquecincta

7 - Olhos pilosos ..............................

7a- Olhos glabros …..................... 10

8 - Escutelo com pêlos pretos ...... eristalis

8a- Escutelo com pêlos dourados, pelo menos na borda posterior ..... 9

9 - Palpo um pouco inflado (Fig. 5c); dois primeiros tergitos com banda apical amarela; escapo e pedicelo amarelos bicincta

9a- Palpo normal (Fig. 9c); pelo menos os três primeiros tergitos com banda apical amarela visível; escapo e pedicelo marrons

exstincta

10-Espinho antenal curto, não alcançando a metade do primeiro flagelômero (Fig. 7a); palpo um

* Espécies com macho conhecido. 
pouco inflado (Fig. 7c); apenas a borda posterior do escutelo com pêlos dourados; constrição no abdômen pronunciada.

coarctata

10a-Espinho antenal excedendoa metade do primeiro flagelômero 11

11 - Asa com enfuscação oblíqua (Fig. 41) longicornis

11 a- Asa sem enfuscação oblíqua ... 12

12 - Pernas pretas; espécie preta com pêlos branco-amarelados no lado do tórax

blaseri

12a- Pernas bicoloridas. 13

13 - Célula r2+3 marrom (Fig. 30); escutelo com pelo menos a borda posterior com pêlos dourados aureoscutellata

13a- Célula $2+3$ hialina, exceto a base e o ápice marrons ................ 14

14 - Tíbia média branca............... 15 14a-Tíbia média enegrecida..............16 15 - Calo frontal mais estreito que a fronte (Fig. 11b); propleura e catatergito dourados

gorayebi

15a- Calo frontal da mesma largura que a fronte na base (Fig. 15b); propleura e catatergito esbranquiçados ........ marginalis

16- Pêlos dos tergitos predominantemente marrons a pretos; tíbia média preta, exceto $1 / 4$ proximal; asa tricolorida (Fig.37)................... fairchildi 16a-Pêlos dos tergitos predominantemente amarelados; tíbia média enegrecida; asa com enfuscação marrom na margem anterior e celula cup, o restante enfumaçado(Fig.31) bequaerti

17- Asa amarela, sem padrão contrastante nigricorpus

17a-Asa com áreas hialinas contrastando com padrão de enfuscação marrom ou amarelo .. 18

18 - Asa marrom, exceto por um triângulo interno ocupando $1 / 2$ a $3 / 4$ das células basais e margem posterior, começando na célula $\mathrm{r} 4$ e extendendo-se até o lobo anal...

18a- Asa diferente 20

19 - Espinho antenal pouco menor que o pedicelo (Fig. 27a);último anulus tão longo quanto largo; células basais na sua maior parte hial in as ( Fig. 53 )......... trigonifera

19a- Espinho antenal 1,5 a 2,0 vezes mais longo que o pedicelo (Fig. 18a); último anulus mais longo que largo; áreas hialinas das células basais restritas ao $1 / 4$ distal da bre $1 / 3$ submediano da bm (Fig.44) albomarginata

20 - Corpo marrom-amarelado; dois primeiros tergitos semitransparentes ..... distincta, sp. $\mathrm{n}$.

20a- Corpo mais escuro; dois primeiros tergitos diferentes

21 - Asa tricolorida: células costal, subcostal, $r 1,1 / 2$ basal da $r 2+3$ e 1/2 da cup amarelas; margem da veia $\mathrm{R} 4$ marrom-escura, $1 / 2$ da célula cup marrom, exceto o centro hialino, o restante da asa hialino ...................... flavicosta

21a- Asa diferente, bicolorida, geralmente com margem anterior largamente escura e margem pos- 
terior hialina ou fracamente enfuscada 22

22 - Asa com fraca enfuscação oblíqua extendendo-se do ápice da célula cup, passando pela base das células $\mathrm{m} 3$ e cuA 1 e célula discal, unindo-se a enfuscação da margem anterior (Fig. 52) ..... ....................... tenuicornis

22a- Asa sem enfuscação oblíqua 23

23 - Corpo marrom com pêlos marrons, sem ornamentação de pêlos amarelo-dourados

adusta

23a- Pêlos amarelos presentes em pelo menos um desses locais: linha sublateral do escudo, escutelo, notopleura, catatergito margem posterior dos tergitos 2 e 3 ......24

24- Tórax com pêlos amarelo-dourados apenas na borda posterior do escutelo e, às vezes, alguns pêlos amarelos póstero-dorsalmente no anepisterno. 25

24a-Pêlos amarelo-dourados presentes, além desses locais, na notopleura 26

25 - Pernas fortemente bicoloridas; espinho antenal longo curvado para baixo (Fig. 20a) ...........cnephosa

25a- Pernas fracamente bicoloridas; espinho antenal menor, quase reto (Fig. 22a)......... diaphorina

26 - Espinho antenal longo, curvado para baixo (Fig. 19a); pernas fortemente bicoloridas; enfuscação da asa inclui a metade basal da célula r5 (Fig. 45)

apicalis

26a- Espinho antenal menor, quase reto
27 - Halter amarelo-creme; abdômen com pruinosidade cinza-azulada apenas no primeiro tergito costaricana

27a- Halter castanho; abdômen com pruinosidade cinza-azulada em todos os tergitos, exceto no terceiro

$(\boldsymbol{\sigma})$ steleiothorax

\section{Acanthocera (Acanthocera) Macquart}

Acanthocera MACQUART, 1834:209. Acanthocera (Mimodynerus) ENDERLEIN, 1922: 350

Acanthocera (Acanthocera); FAIRCHILD, 1969: 209; 1971:

59 (catálogo).

FAIRCHILD (1969) revalidou Mimodynerus Enderlein com status de subgênero no gênero Acanthocera, e incluiu as espécies: anacantha, eristalis, kroeberi, intermedia e quinquecincta, com os seguintes atributos: ausência de espinho ou proeminência dorsal no primeiro flagelômero, fronte larga, calo frontal transverso e palpo incomumente inflado. Estes caracteres, exceto a ausência de espinho ou angulação dorsal no primeiro flagelômero, estão presentes em algumas espécies de $A$. (Acanthocera). Em adição, os caracteres do subgênero Acanthocera estão presentes em A. (Mimodynerus). Conclui-se, portanto, que $A$. (Mimodynerus) é sinônimo de $A$. (Acanthocera) como já havia sido postulado por KROEBER (1934).

O subgênero Acanthocera tem como caracteres: tamanho 9,0 - 16,0 $\mathrm{mm}$; antena visivelmente maior que a 
tíbia posterior; flagelo maior que escapo e pedicelo juntos; escapo longo, por vezes tão longo quanto o primeiro flagelômero; estilo robusto, da mesma largura e 1,5 a 2,0 vezes maior que o primeiro flagelômero; olhos, na maioria das espécies, glabros; constrição do abdômen pode apresentar-se pronunciada; pelo menos o primeiro segmento abdominal com cinta branca ou amarela. Distribui-se na região neotropical, praticamente em todas as áreas florestadas da América do Sul.

Acanthocera (Acanthocera) anacantha Lutz \& Neiva

(Figs. 2a-c, 29)

Acanthocera anacantha Lutz \& Neiva, 1915 (in LUTZ, 1915): 65, Pr. 19, Fig. 8 (\$); SURCOUF, 1921: 90; FAIRCHILD. 1939: 18 (part); 1961a: 203 (Lectótipo). Mimodynerus anacanthus; ENDERLEIN, 1922: 350 (em chave).

Spheciogaster anacantha; KROEBER,

1928: 80 (determinação errônea). Spheciogaster anacanthus; KROEBER, 1934: 253 (catálogo).

Acanthocera intermedia; FAIRCHILD, 1939: 18 (part).

Acanthocera (Mimodynerus) anacantha; FAIRCHILD, 1969: 209; 1971: 59 (catálogo).

Diagnose: Tamanho 11,0 - 13,3 $\mathrm{mm}$. Espécie preta. Fronte larga (Fig. 2b). Indice frontal 0.9. Antena (Fig. 2a) sem espinho, proeminência ou angulação no primeiro flagelômero. Palpo robusto (Fig. 2c). Asa (Fig. 29). Pernas marrom-escuras exceto os tarsos médios e posteriores mais claros. Tergitos 1 e 2 com banda subapical preta e apical branca com pêlos amarelos. Constrição no abdômen pronunciada.

Macho: desconhecido.

Distribuição: Brasil (São Paulo, Mato Grosso do Sul, Goiás).

Material examinado: [BRASIL], Säo Paulo, Noroeste de São Paulo, 1910, N..., NT-335, Inst. O. Cruz, coleção A. Lutz (flagelo esquerdo ausente, asa direita em microlâmina) (Lectótipo $\mathbf{9}$, FIOC); i.1908, NT-337 (Paralectótipo, 9 FIOC); x.1908, NT338 (Paralectótipo 9, FIOC); 1910, (4 Paralectótipos Q, FIOC); NT-336 (Paralectótipo Q, FIOC); 60 \$ (54 MZUSP, 2 MPEG, 2 INPA, 2 USNM).

Acanthocera (Acanthocera) aureoscutellata Henriques \& Rafael

(Figs. 3a-c, 30)

Acanthocera coarctata; LUTZ, 1915 :

59 (part); ENDERLEIN, 1925:

333; FISCHER, 1939: 334 ( $\boldsymbol{\sigma}$ ); FAIRCHILD, 1939: 24 (revisão); BARRETTO, 1947: 90 ( $\boldsymbol{\sigma}$ ); BOUVIER, 1952: 590 (determinações errôneas).

Spheciogaster coarctata; KROEBER,

1928: 82 (determinação errônea). Acanthocera (Acanthocera) coarctata: COSCARÓN, 1978: 30 (determinação errônea).

Acanthocera (Acanthocera) aureoscutellata HENRIQUES \& RAFAEL, 1992: 3, Figs. la-c, 5 (\$).

Diagnose: Tamanho 9,6 - 12,6 $\mathrm{mm}$. Espécie marrom-escura com pruinosidade amarela e pêlos dourados na propleura, notopleura, anepisterno, catatergito, linha sublateral e escutelo. Índice frontal 1.7. Espinho anterial de 
tamanho médio, reto, com ápice que ultrapassa a metade do primeiro flagelômero (Fig. 3a). Asa (Fig. 30) com enfuscação marrom-clara na área costal e célula cup.

A. aureoscutellata é semelhante morfologicamente a $A$. coarctata, mas difere pelo tamanho maior do espinho antenal, palpo mais delgado (Fig. 3c), propleura e catatergito com pêlos dourados, dois primeiros segmentos abdominais mais escuros, constrição abdominal menos pronunciada.

Macho: Similar à fêmea, com palpo porreto, olhos contíguos e pêlos do corpo mais longos. Descrito adequadamente por FISCHER (1939) e BARRETTO (1947).

Distribuição: Brasil (Goiás, Mato Grosso do Sul, Minas Gerais, São Paulo, Rio de Janeiro, Paraná), Paraguai, Argentina (Corrientes).

Material examinado: o mesmo da descrição (HENRIQUES \& RAFAEL, 1992).

Acanthocera (Acanthocera) bequaerti

Fairchild \& Aitken

(Figs. 4a-c, 31)

Acanthocera marginalis; BEQUAERT,

1944: 21 (determinaçao errônea). Acanthocera bequaerti FAIRCHILD \& AITKEN, 1960: 3, Fig. $2(\mathbf{9})$; FAIRCHILD, 1964: 171; 1966c:

375 (como sinônimo de $A$. formosa). Acanthocera (Acanthocera) bequaerti; FAIRCHILD, 1971: 59 (como sinônimo de A. marginalis, catálogo).

Diagnose: Tamanho 9,5 - 12,0 $\mathrm{mm}$. Índice frontal 1.5. Espécie semelhante morfologicamente a $A$. marginalis, diferindo pela tíbia média enegrecida, fronte (Fig. 4b) mais convergente no vértice, asa (Fig. 31) largamente enfumaçada, banda terminal do tergito 3 formada por pêlos brancos e abdômem coberto predominantemente por pêlos amarelados.

Macho: Desconhecido.

Distribuição: Trinidad, Venezuela, Suriname.

Material examinado: TRINIDAD, Arima, 12.vi.1953, W.G. Downs col. (Parátipo 9, FSCA); 29.vii.1953 (Parátipo, 9CAS); 20.v.1954 (Parátipo ९, FSCA); 2.vi.1954 (Parátipo Q. FSCA); Cumuto, 7.i.1941, E. Rozeboom col., marginalis, det. Philip, 1943 (Parátipo $\mathbf{8}$, FSCA); Sangre Grande, Melajo forest, 9.v.1955, T.H.G. Aitken col. (Parátipo 9 , FSCA); Vega de Oropuche, 18.vi.1957 (Parátipo ?, CAS), Tabaquite, Charuma forest, 28.vii.1955 (2 Parátipos ?, USNM); ii.1950, F.W. Urich col. (\$, USNM); Fort Reid, 21.vii.1961 ( 9 , USNM); Nariva, swamp, Bush forest, 8.viii.1963, Aitken col. ( $\boldsymbol{\$}$, USNM); [St. Andrew], Mitan, vii.1959 ( $\boldsymbol{Q}$, USNM); Sangre Grande, Rio Grande forest, 29.vi.1959 (3 $\$$ ९, CAS); Vega de Oropuche. 23.vi.1959 (\$, USNM); 7.viii.1959 (\$, CAS); Arima, Valley rain forest, 20.vi.1977, P. Feinsinger col. (2 ?, USNM); San Rafael, 1973, Thomas Rogers col. ( $\mathbf{9}$, FSCA); idem, Tucuche, 21.v.1925, F.W. Rohwer col. ( 9 , USNM); VENEZUELA, Bolivar, Rio Karuai, n. Kavanayen, 1000m, 1011.viii.1970, R. Dietz col. (5 9 \%, USNM); SURINAME, matta, ex. man, 15.i.1960, D. Geijjskes col. (\$, FSCA); Zanderij, 5.vii.1961, Geijjskes col. ( $\mathbf{9}$. MPEG). 
Localidade típica: Trinidad, Sangre Grande.

Acanthocera (Acanthocera) bicincta

Henriques \& Rafael

(Figs.5a-c, 32)

Acanthocera (Acanthocera) exstincta; STRICKMAN, 1982: 401 (determinação errônea).

Acanthocera (Acanthocera) bicincta HENRIQUES \& RAFAEL, 1992: 5, Figs. 2a-c, 6 (9).

Diagnose: Tamanho $9,0 \mathrm{~mm}$. Espécie preta com pêlos dourados na linha sublateral, notopleura, escutelo, propleura, anepisterno e catatergito. Olhos pilosos. Antena (Fig. 5a) com proeminência dorsal no primeiro flagelômero. Palpo (Fig. 5c) um pouco inflado. Fronte (Fig. 5b) larga, Índice frontal 1.0. Abdômen com banda terminal amarela nos tergitos 1 e 2 .

Espécie semelhante morfologicamente a $A$. exstincta, diferindo desta pelo palpo menos delgado, escapo e pedicelo amarelados, enfuscação da asa mais escura (Fig. 32) e apenas duas bandas claras no abdômen.

Macho: Similar à fêmea com palpo porreto, olhos contíguos e pêlos do corpo maiores.

Distribuição: Brasil (Rio Grande do Sul), Paraguai.

Material examinado: $O$ mesmo da descrição (HENRIQUES \& RAFAEL, 1992).

Acanthocera (Acanthocera) blaseri

Fairchild

(Figs. 6a-c, 33)

Acanthocera blaseri FAIRCHILD, 1939: 21, Figs. 5, 11, 17 (\$). Acanthocera (Acanthocera) blaseri;
FAIRCHILD, 1971 :

(catálogo).

Diagnose: Tamanho 10,5 mm. Espécie preta com pêlos amarelos no escutelo e anepisterno. Índice frontal 1.8. Espinho antenal metade do comprimento do primeiro flagelômero (Fig. 6a). Pernas unicoloridas, marrom-escuras com pêlos brancos esparsos. Segmentos abdominais com cintas apicais brancas, mais conspícuas nos segmentos 2 e 3 .

Os espécimes estudados, segundo FAIRCHILD (1939), foram preservados em álcool e talvez as cores não sejam as naturais. $\mathrm{O}$ abdômen apresenta-se um pouco deformado em ambos os espécimes.

Macho: Desconhecido.

Distribuição: Brasil (Minas Gerais).

Material examinado: BRASIL, Minas Gerais, Barro Alto, xi.1931, J. Blase col. (Holótipo $\mathbf{9}$, Parátipo $\mathbf{9}$ MCZ).

Acanthocera (Acanthocera) coarctata (Wiedemann)

(Figs. 7a-c, 34)

Haematopota coarctata WIEDEMANN, 1828: 578 ( 9 ); WALKER, 1854: 295; KERTÉSZ, 1900: 31 (catálogo).

Acanthocera coarctata; RICARDO, 1904: 363; SURCOUF \& GONZALES-RINCONES, 1912: 90; LUTZ, 1915: 59 (part); BRÈTHES, 1921: 35; FAIRCHILD, 1939: 24 (part); COSCARÓN, 1967: 113 (tab. da Argentina); FAIRCHILD, 1967a: 76 (spp. Wiedemann). 
Spheciogaster lutzi ENDERLEIN, 1922:

349 ( $\boldsymbol{P}$, em chave); 1925: 333

(descrição); FAIRCHILD, 1966a:

03 (spp. Enderlein).

Spheciogaster

anacanthus;

KROEBER, 1928: 80, Fig. 2;

(nec Lutz \& Neiva).

Spheciogaster coarctatus; KROEBER,

1934: 253 (catálogo).

Acanthocera lutzi; FAIRCHILD,

1939: 22 (revisão); BOUVIER,

1952: 582 (distribuição).

Acanthocera vespoides BARRETTO,

1947: 104, Figs. 6, 14 (9).

Acanthocera (Acanthocera) vespoides;

PAPAVERO, 1971: 155 (como sinônimo de $A$. lutzi);

FAIRCHILD, 1971: 59 (como

sinônimo de $A$. lutzi, catálogo).

Acanthocera (Acanthocera) lutzi;

FAIRCHILD, 1971: 59

(catálogo), SINONÍMIA NOVA.

Diagnose: Tamanho $12,9 \mathrm{~mm}$. Espécie marrom a preta. Índice frontal 1.5. Olhos glabros. Antena com espinho curto (Fig. 7a). Palpo um pouco inflado (Fig. 7c). Borda posterior do escutelo com pêlos amarelos. Constrição do abdômen pronunciada. Dois primeiros segmentos abdominais marrom-claros, por vezes semitransparentes.

Macho: Desconhecido. FISCHER (1939) e BARRETTO (1947) descreveram o macho de coantata, mas na realidade os espécimes pertencem à espécie 4 . aureoscutellata.

Distribuição: Brasil (Mato Grosso do Sul, Minas Gerais, Rio de Janeiro, São Paulo, Paraná), Paraguai.

Material examinado: BRASIL, $A$. coarctata, Mus. Westerm., Type (Holótipo $\mathbf{Q}$, UZM) (asa direita em microlâmina, terminália em microtubo com glicerina); Mato Grosso, Rhode col., Spheciogaster lutzi, Type, Enderl.9, det. Dr. Enderlein, 1922, Spheciogaster anacantha (Lutz), det. Kroeber, 1928, Zool. Muz. Berlin (estilo esquerdo e asa direita ausentes, terminália em microtubo com glicerina) (Holótipo Q, Spheciogaster lutzi, ZMHU); São Paulo, Juquiá, Faz. Poço Grande, ix.1945, Barretto col., n.sp. ${ }^{\circ}$ 3 , vespoides (terminália em microtubo com glicerina) (Holótipo $\mathbf{9}$ Parátipo $\mathbf{9}$ Acanthocera vespoides, MZUSP); J. da Boa Vista, Fda. Santa Carolina, 6.iv.1947 (Paratipo P, A. vespoides, MZUSP); Sabauma, 10.vii.1908 (?, FSCA); Albuquerque Lins, 19.ix.1913, Homotype of Spheciogaster lutzi, Fairchild det., 1964 ( 9 , FSCA); Salesópolis, 850m, 11.ix.1963 (2 \$9, FSCA); 16.x.1963 (\$, MZUSP); 17.viii.1964 (2 Q९, MZUSP); 1.ix.1967 ( $\mathbf{Q}$, MZUSP); Rio de Janeiro, viii.1938, M.E.S. Bras. col. (Parátipo 9, A. vespoides, MZUSP); x.1937 (\$, USNM); viii.1938 (\$) USNM); ix.1938 ( $\mathbf{Q}$, FSCA); Paraná, Vargem Grande, xi.1944, B. Hertel col., 24826, A. lutzi, Coscarón det., 1975 (Parátipo Q, A. vespoides, MZUSP); Marumbi, ix.1946, Hatschabach col., Acanthocera lutzi, Coscarón det., 1975, 24825 (Parátipo 9, A. vespoides, MZUSP); Minas Gerais, Pouso Alegre, 18.ix.1962 (\$, MPEG); PARAGUAI, Vilarrica (sic), viii.1938 ( $\boldsymbol{Q}$, USNM); ix.1938 (\$, USNM). 
Acanthocera (Acanthocera) eristalis Lutz

(Figs. 8a-c, 35)

Acanthocera eristalis LUTZ, 1915: 68 , Pr. 19, Fig. 11 ( 9 ); SURCOUF, 1921: 90 ; FAIRCHILD, 1939: 18 (revisão); 1961a: 204 (spp. Lutz).

Lutziella eristalis; ENDERLEIN, 1925: 337 (distribuição); KROEBER, 1928: 94 (nec Lutz); 1934: 254 (catálogo).

Acanthocera (Mimodynerus) eristalis;

FAIRCHILD, 1971: 59

(catálogo).

Diagnose: Tamanho 9,0 - 11,0 $\mathrm{mm}$. Espécie preta com pêlos amarelodourados na propleura, posteriormente na notopleura, póstero-dorsalmente no anepisterno e catatergito. Fronte larga (Fig. 8b). Índice frontal 0.9. Olhos pilosos. Antena (Fig. 8a). Palpo marrom (Fig. 8c). Pernas marrons, exceto as tíbias média e posterior, mais claras. Segmentos abdominais com banda terminal amarela, exceto o terceiro tergito, ainda assim pode apresentar-se muito estreita neste segmento.

Espécie semelhante morfologicamente a $A$. quinquecincta, diferindo pela presença dos pêlos dourados na pleura e padrão de cor das pernas.

Macho: Desconhecido.

Distribuição: Brasil (São Paulo, Santa Catarina).

Material examinado: [BRASIL], Santa Catharina (sic), Serra da Bocaina, xii.1912, NT 348, Inst. O. Cruz, coleção A. Lutz (asa direita em microlâmina) (Holótipo P. FIOC); São Paulo, 1955 (9. MZUSP).
Acanthocera (Acanthocera) exstincta (Wiedemann)

(Figs. 9a-c, 36)

Haematopota exstincta WIEDEMANN, 1828: 214 (9).

Acanthocera exstincta; WALKER, 1854: 268; KERTÉSZ, 1900: 29 (catálogo); HUNTER, 1901: 137 (catálogo); RICARDO, 1904: 393; LUTZ, 1915: 58 (trad. descrição); BRÈTHES, 1921: 36; SURCOUF \& GONZALES-RINCONES, 1912: 53; SURCOUF, 1921: 90; ENDERLEIN, 1925: 333 (distribuição); KROEBER, 1928: 88 (redescrição); 1934: 254 (catálogo); FAIRCHILD, 1939: 20 (revisão); COSCARON, 1966: 58 (distribuição); FAIRCHILD, 1967a: 76 (spp. Wiedemann); COSCARÓN, 1967: 113 (tab. Argentina).

Acanthocera (Acanthocera) exstincta;

FAIRCHILD, 1971: 59 (catálogo).

Diagnose: Tamanho: $9.6-11,7$ $\mathrm{mm}$. Espécie preta com pêlos dourados na linha sublateral, propleura, pósterodorsalmente na notopleura, metade posterior do escutelo, dorsalmente no anepisterno, anatergito e catatergito. Olhos pilosos. Fronte larga (Fig. 9b). Índice frontal 1.0. Antena com espinho curto (fig. 9a). Segmentos abdominais com banda apical esbranquiçada. Pemas marrons a pretas, exceto as tíbias. esbranquiçadas e os tarsos, pardacentos.

Macho: Similar a fêmea com palpo porreto, olhos contíguos, pêlos do corpo maiores.

Distribuição: Brasil (Rio Grande do Sul), Argentina (Corrientes), Uruguai. 
Material examinado: BRASIL, Rio Grande do Sul, Pelotas, 4.v.1960 (O MZUSP); 7.ii.1961 (2 ९९, BMNH); 11.ii.1961 (\$, BMNH); 2.v.1962 (asa direita em microlâmina) ( $\boldsymbol{\$}$, MZUSP); 1.ii.1963 (2 Q९, MZUSP); ARGENINA Corrientes, Mercedes, 16.xii.1941, Homotype of A. eristalis, Fairchild det., 1963, A. exstincta Wied., Coscarón det., ( $\mathbf{9}$, MLP); URUGUAI, Artigas, Rio Curaeim, Sepulturas, 11.iii.1966 (P, MLP).

Acanthocera (Acanthocera) fairchildi Henriques \& Rafael

(Figs. 10a-c, 37)

Acanthocera (Acanthocera) fairchildi HENRIQUES \& RAFAEL, 1992: 6, Figs. 3a-c, 7 ( $)$ ).

Diagnose: Tamanho 11,0 - 14,4 $\mathrm{mm}$. Índice frontal 1.6. Espécie preta com pêlos dourados na linha sublateral notopleura e escutelo. Asa tricolorida (Fig. 37). Tíbia média preta. Abdômen com pêlos marrons a pretos. Tergitos 1 e 2 com banda apical amarela.

Espécie semelhante morfologicamente aos exemplares mais escuros de A. marginalis (veja variações em marginalis), mas difere pela tíbia média enegrecida, ausência de banda pruinosa branca no terceiro tergito, tamanho maior e asa tricolorida. Também é semelhante a $A$. bequaerti, diferindo pela área central da asa amarelada e não enfumaçada, tamanho maior, face preta, presença de pruinosidade cinza-azulada no tergito 3 , abdômen com pêlos marrons a pretos.

Macho: Similar a fêmea, palpo porreto, olhos contíguos, pêlos do corpo maiores.
Distribuição: Brasil (Pará, Amazonas, Rondônia, Acre); leste do Peru e Bolívia.

Material examinado: $\mathrm{O}$ mesmo da descrição (HENRIQUES \& RAFAEL, 1992); Acre, Porto Acre, 21.x-10.xi.1991 (89 Q९, MPEG).

Dados bionômicos: Foi observado o comportamento de ataque desta espécie em eqüino: a fêmea pousa no dorso do animal (no final das vértebras torácicas), imediatamente conseguindo repasto, adotando posição quase perpendicular ao corpo do hospedeiro. Ocorrem casos de ataque ao homem. A. fairchildi é coletada de setembro a dezembro, com relativa abundância em outubro e novembro. Predomina no estrato superior da floresta.

Acanthocera (Acanthocera) gorayebi Henriques \& Rafael

(Figs. 11a-c, 38)

Acanthocera (Acanthocera) gorayebi HENRIQUES \& RAFAEL, 1992: 8, Figs, 4a-c, 8 (\$).

Diagnose: Tamanho 9,7 - 12,6 mm. Espécie marrom-escura com pêlos dourados na linha sublateral, propleura, anepisterno, catepisterno, catatergito e escutelo. Calo frontal mais estreito que a fronte (Fig. 11b). Índice frontal 1.8. Asa (Fig. 38), em alguns espécimes estudados, com célula rl toda enfuscada.

Espécie semelhante morfologicamente a A. marginalis, mas difere pelo calo frontal mais estreito que a fronte, catatergito e catepisterno com pêlos dourados.

Macho: Similar à fêmea com palpo porreto, olhos contíguos, pêlos do corpo maiores. 
Distribuição: Guiana, Suriname, Brasil (Amapá, Pará, Amazonas, Rondônia, Mato Grosso, Acre), leste do Peru.

Material examinado: $\mathrm{O}$ mesmo da descrição (HENRIQUES \& RAFAEL, 1992); Acre, Porto Acre, 21.x-10.xi.1991 (8 Q9, MPEG).

Acanthocera (Acanthocera) intermedia Lutz

(Figs. 12a-c, 39)

Acanthocera intermedia LUTZ, 1915: 66, Pr. 19, Fig. 9 (9); SURCOUF, 1921: 90; FAIRCHILD, 1939: 18 (sob sinonímia de A. anacantha, revisão); 1961a: 204 (designação de Lectótipo): 233 (revalidação).

Mimodynerus intermedius; ENDERLEIN, 1925: 337 (distribuição); KROEBER, 1928: 94 (discussão). Lutziella intermedia; KROEBER, 1934: 254 (catálogo).

Acanthocera (Mimodynerus) intermedia;

FAIRCHILD, 1971: 59 (catálogo).

Diagnose: Tamanho 9,6 - 12,5 $\mathrm{mm}$. Espécie marrom a preta com a linha sublateral amarelada. Pêlos amarelos na notopleura e escutelo. Olhos glabros. Fronte (Fig. 12b). Indice frontal 2.0. Antena sem espinho ou protuberância no primeiro flagelômero (Fig. 12a). Padrão de enfuscação da asa variável. Tíbia anterior e posterior com $1 / 2$ proximal branca, o restante enegrecido.

Macho: Desconhecido.

Distribuição: Brasil (Pará, Rondônia, Tocantins).

Material examinado: [BRASIL, Goiás], M. do Peixe, viii.1912, NT 351, Inst. O. Cruz, coleção A. Lutz (flagelo direito ausente, flagelo esquerdo colado à cabeça, asa direita em microlâmina) (Lectótipo 9, FIOC); l.ix.1912, NT 350 (Paralectótipo ?. FIOC); Pará, Serra Norte, N1, canga, 24-27.vi.1985 (9, MPEG); Ig. Salobo, 14.viii.1984 (\$, MPEG); 23.viii. 1984 (9, MPEG); Ig. Fofoca, 17 20.viii.1984 (2 9 , MPEG, , INPA); Est. Manganês, 19-22.viii.1984 (\$. MPEG); São João de Pirabas, Boa Esperança (8 $\mathbf{9}$, MPEG, $\mathbf{P}$, INPA); Rondônia, Ouro Preto do Oeste, Linha 212, lote 36, gleba 21-B, 4.ix.1986 (2 १९, MPEG).

Variações: As 17 fêmeas do Pará e Rondônia são mais escuras que os Tipos. O padrão de enfuscação da asa varia desde apenas a área costal e célula cup marrons, até quase toda marrom, exceto pelo lobo anal mais claro, e ápice das células cuA $1,1 / 2$ distal da $\mathrm{m} 1, \mathrm{~m} 2$, $\mathrm{m} 3, \mathrm{r} 4$ e r5 hialinos, semelhante a asa de A. longicornis.

Acanthocera (Acanthocera) kroeberi Fairchild

(Figs. 13a-c, 40)

Lutziella eristalis; KROEBER, 1928:

94; 1934: 254 (catálogo)

(determinaçao errônea).

Acanthocera kroeberi FAIRCHILD, 1939: 20, Figs. 7, 22 (9).

Acanthocera (Mimodynerus) kroeberi;

FAIRCHILD, 1971: 60 (catálogo).

Diagnose: Tamanho $11,2 \mathrm{~mm}$. Espécie preta com cintas apicais amarelas nos tergitos 1, 2, 4-7 e esternitos 3-7. Fronte (Fig. 13b) larga. Índice frontal 0.9. Calo transversal. Olhos pilosos. Palpo (Fig. 13c) robusto. 
Antena (Fig. 13a) sem espinho ou protuberância, marrom a preta, exceto o escapo amarelo. Pernas enegrecidas, exceto os tarsos médio e posterior esbranquiçados. Asa (Fig. 40).

A. kroeberi é semelhante morfologicamente a $A$. eristalis, mas difere pela ausência de proeminência dorsal no primeiro flagelômero e tufos de pêlos amarelos na pleura.

Macho: Desconhecido.

Distribuição: Paraguai (Villa Rica).

Material examinado: PARAGUAI, Villa Rica, F. Shade col., Type, Acanthocera kroeberi, n.n. for $A$. eristalis; Kroeber nec Lutz (asa direita em microlâmina) (Holótipo $\mathbf{9}, \mathrm{MCZ}$ ); 19?9, A. (A.) kroeberi Fchld., Fairchild det., 1971 ( $\boldsymbol{Q}$, USNM).

Acanthocera (Acanthocera) longicomis

(Fabricius)

(Figs. 14a-c, 41)

Tabanus longicornis FABRICIUS, 1775: $731(\mathbf{Q})$; 1805: 103.

Haematopota triangularis WIEDEMANN, 1828: 213 (L).

Tabanus pictipennis MACQUART, 1834: 199 (9).

Acanthocera longicomis; MACQUART, 1834: 209; WALKER, 1854: 267; KERTÉSZ, 1900: 29 (catálogo); HUNTER, 1901: 138 (catálogo); RICARDO, 1904: 363; LUTZ, 1915: 56 (redescrição); SURCOUF, 1921: 90; ENDERLEIN, 1925: 333 (distribuição); KROEBER, 1928: 90 (redescrição); 1934: 254 (catálogo); FAIRCHILD, 1939: 23 (revisão); 1966b: 18 (spp. Fabricius).

Dichelacera longicomis MACQUART,
1838: 114, Pr. 16, Fig. 12 (9); WALKER, 1854: 150.

Acanthocera (Acanthocera) longicomis; FAIRCHILD, 1971: 59 (catálogo).

Diagnose: Tamanho 11,0 - 16,0 $\mathrm{mm}$. Espécie marrom a preta com pêlos amarelos na notopleura, anepisterno, 1/ 2 posterior do escutelo. Fronte (Fig. 14b) mais alta que larga. Índice frontal 2.2. Olhos glabros. Antena (Fig. 14a) com espinho dorsal no primeiro flagelômero. Asa (Fig. 41) com enfuscação oblíqua, unindo a enfuscação costal com a da célula cup. Abdômen com cinta apical amarela nos tergitos 1 e 2. Esternito 2 com cinta apical branca.

Macho: Similar à fêmea, sendo mais claro inclusive a enfuscação da asa, palpo porreto, olhos contíguos e pêlos do corpo maiores.

Distribuição: Brasil (Paraíba, Minas Gerais, Espírito Santo, Rio de Janeiro, São Paulo, Paraná, Santa Catarina).

Material examinado: 9698 (2 MPEG, 1 INPA, 6 FSCA, 15 USNM, 7 CAS, 11 UFPR, 54 MZUSP); $1 \sigma$ (FSCA).

Holótipo perdido (FAIRCHILD, 1971).

Acanthocera (Acanthocera) marginalis

Walker

(Figs. 15a-c, 42)

Acanthocera marginalis WALKER, 1854: 268, Pr. 5 (9); KERTÉSZ, 1900: 29 (sob sinonímia de $A$. exstincta, catálogo); RICARDO, 1904: 363; LUTZ, 1915: 60 (redescrição); ENDERLEIN, 1925: 333 (distribuição); 
BEQUAERT, 1926: 219; Roeder col., type, M.L.U. Halle, W.B. KROEBER, 1928: 86 Zoologie, S-Nr (Holótipo P, (redescrição); 1934: 254 Acanthocera formosa, Halle); cotype (catálogo); FAIRCHILD, 1939: (Parátipo Q, A. formosa, Halle); 26 (revisão).

Acanthocera formosa KROEBER, 1930: 79 (\$); 1934: 254 (catálogo); FAIRCHILD, 1939: 26 (revisão); 1966c: 332 (spp. Kroeber); 1971: 59 (sob sinonímia de A. (A.) marginalis, catálogo); 1975: 261.

Acanthocera (Acanthocera) marginalis; FAIRCHILD, 1971: 59 (catálogo).

Diagnose: Tamanho 9,5 - 12,3 $\mathrm{mm}$. Espécie marrom a marrom-escura com pêlos dourados na linha sublateral, escutelo, dorsalmente na notopleura e anepisterno. Propleura e catatergito com pruinosidade amarelada e pêlos claros. Abdômen marrom, tergitos 1-3 e esternitos 2 e $3 \mathrm{com}$ cinta apical amarela. Índice frontal 1.9. Calo tão largo quanto a fronte na base. Olhos glabros. Antena (Fig. 15a) com espinho dorsal no primeiro flagelômero. Palpo (Fig. 15c) marrom-claro. Asa (Fig. 42). Tíbia média branca.

Macho: Similar à fêmea com palpo porreto, olhos contíguos, pêlos do corpo maiores.

Distribuição: Colômbia, Suriname, Guiana Francesa, Brasil (Roraima, Amapá, Pará, Acre, Amazonas), Equador, Peru, Bolívia.

Material examinado: BRASIL, Pará, H.W. Bates col., 15-147, Acanthocera marginalis, Holotype (asa direita em microlâmina) (Holótipo 9, BMNH): PERU, Iquitos, Amazonenstr. (sic), 4.ii.1921. V. [BRASIL], Amazon. [Pará], Itaituba, cotype (Parátipo $\mathbf{Q}$, A. formosa, Halle); 224 \$९ (1 MLP, 31 FSCA, 2 CAS, 1 BMNH, 90 INPA, 195 MPEG, 3 USNM); $1 \boldsymbol{\sigma}$ (INPA).

Variações: 115 fêmeas, inclusive o Holótipo de $A$. formosa, são mais escuras que o Holótipo de marginalis. 11 fêmeas de Madre de Dios, Peru (FSCA) apresentam a propleura com pruinosidade esbranquiçada e catatergito com pêlos amarelos. A enfuscação da área costal da asa pode alcançar a célula $r 2+3$ e mais raramente o ápice da $\mathrm{r} 4$.

Acanthocera (Acanthocera) quinquecincta Lutz

(Figs. 16a-c, 43)

Acanthocera quinquecincta LUTZ, 1915: 67, Pr. 19, Fig. 10 (\$): SURCOUF, 1921: 90: FAIRCHILD, 1939: 18 (revisão); BOUVIER, 1952: 591 (distribuição); FAIRCHILD, 1961a: 205 (designação de Lectótipo).

Lutziella quinquecincta; ENDERLEIN.

1925: 337 (distribuição): KROEBER, 1928: 96 (redescrição); 1934: 255 (catálogo).

Acanthocera

(Mimodvnerus)

quinquecincta; FAIRCHILD, 1971:

60 (catálogo).

Diagnose: Tamanho $10 \mathrm{~mm}$. Espécie preta com pêlos dourados dorsalmente no anepisterno, borda posterior dos tergitos 1, 4-7 e esternitos 2 - 
7. Pruinosidade amarelada pósterodorsalmente na notopleura. Fronte larga (Fig. 16b). Índice frontal 0.8 . Olhos pilosos. Antena (Fig. 16a) sem espinho ou protuberância no primeiro flagelômero. Asa (Fig. 43). Pernas marrons exceto as coxas pretas.

Macho: Desconhecido.

Distribuição: Brasil (São Paulo).

Material examinado: [BRASIL], Säo Paulo, noroeste de São Paulo, 1910, N..., coleção do Instituto Osw. Cruz, Lectotype, NT 366, coleção A. Lutz (espécime danificado) (Lectótipo \$, Paralectótipo $\mathbf{Q}$, FIOC); Campos do Jordão, xii.1995 (2 9 Q, MZUSP).

Variações: 2 fêmeas (MZUSP) não apresentam a pruinosidade amarela na notopleura e apresentam uma estreitíssima banda apical amarela no tergito 2. 1 fêmea (MZUSP) possui pruinosidade amarela na linha sublateral.

\section{Acanthocera (Nothocanthocera)} (Fairchild), comb.n.

Dichelacera (Nothocanthocera) FAIRCHILD, 1969: 209; 1971: 65 (catálogo); WILKERSON, 1981: 64 (subgen. Nothocanthocera). Espécie-tipo Acanthocera tenuicornis Lutz (des. orig.)

Nothocanthocera foi criado por FAIRCHILD (1969) para englobar as espécies de Acanthocera com escapo "mais curto" e por este atributo foi tratado como subgênero de Dichelacera Macquart. WILKERSON (1981) reconhece o subgênero e descreve duas espécies: adusta e flavicosta. Aqui o subgênero Nothocanthocera é transferido ao gênero Acanthocera, por apresentar mais caracteres deste do que daquele, como por exemplo: labela parcialmente esclerotinizada, aspecto vespiforme e antena relativamente longa. Dichelacera melanoptera Hine não se enquadrou nos atributos do gênero Acanthocera. O estudo de espécimes, inclusive o Holótipo (AMNH), demonstrou a espécie pertencer ao gênero Dichelacera, permanecendo temporariamente "incertae sedis" nos seus subgêneros, o que deve ser tratado em trabalhos subsequentes.

O subgênero Nothocanthocera distingui-se dos demais pelo seguinte conjunto de atributos: Antena nunca maior que a tíbia posterior, escapo menor que o primeiro flagelômero, os anuli em vista dorsal são mais estreitos que o primeiro flagelômero, espinho antenal sempre presente, olhos glabros, tamanho 9,0 - 17,7 mm, leve constrição no abdômen e face pouco inflada. É um grupo disruptamente distribuido no neotrópico. A maioria das espécies é encontrada no sudeste do Brasil, próximo ao litoral, mais precisamente na Mata Atlântica; duas espécies a oeste dos Andes (Venezuela e Colômbia); outras duas no norte da Bacia Amazônica e uma isolada na América Central.

Acanthocera (Nothocanthocera) adusta (Wilkerson), comb. $\mathrm{n}$. (Figs. 17a-c)

Dichelacera (Nothocanthocera) adusta WILKERSON, 1981: 69, Figs. 1a-c, 8 ( $($ ).

Diagnose: Tamanho 9,0 - 11,5 $\mathrm{mm}$. Espécie marrom com pêlos 
marrons. Espinho antenal curto (Fig. 17a). Face lisa brilhante. Palpo (Fig. 17c) delgado. Índice frontal 2.2. Asa com enfuscação marrom na margem anterior, incluindo $1 / 3$ basal da célula r5 e mais fracamente na célula cup. Apesar de não apresentar o aspecto vespiforme, decidimos pela sua inclusão no gênero Acanthocera, face aos caracteres de labela parcialmente esclerotinizada, padrão de enfuscação da asa, e os caracteres da cabeça apresentados em figuras, que a confirmam como integrante do subgênero Nothocanthocera.

Macho: Desconhecido.

Distribuição: Brasil (Minas Gerais).

Material examinado: [BRASIL], Minas Gerais, Cipó, 20.xi.1938, Martins col., eye unbanded (espécime mal preservado, corpo quase sem pêlos, faltam as pernas média e posterior esquerdas, asa esquerda ausente, asa direita com margem posterior danificada) (Parátipo 9 , FSCA).

Condição do Holótipo: Segundo WILKERSON (1981) está danificado. Faltam o flagelo esquerdo, a perna anterior esquerda, o tarso médio direito, metade da tíbia posterior e tarsos posteriores. Em adição, o tórax está um pouco comprimido dorsolateralmente e o espécime está fixado com cola no alfinete.

Observação: o Holótipo não foi encontrado no MZUSP, local indicado como depósito por Wilkerson.

Acanthocera (Nothocanthocera) albomarginata (Kroeber), comb.n. (Figs. 18a-c, 44)
Acanthocera trigonifera; KROEBER, 1928: 89 (nec Schiner).

Spheciogaster albomarginatus KROEBER, 1930: 76, Figs. 17, 18 (9); 1934: 253 (catálogo); FAIRCHILD, 1966c: 355 (spp. Kroeber).

Acanthocera albomarginata;

FAIRCHILD, 1939: 20 (revisão).

Dichelacera (Nothocanthocera) albomarginata; FAIRCHILD, 1969: 209; 1971: 65 (catálogo); 1975: 264 (spp. Kroeber); WILKERSON, 1979: 260 (reg. Colômbia); 1981: 66 (em chave).

Diagnose: Tamanho 12,6 - 15,6 $\mathrm{mm}$. Espécie preta com distinto triângulo preto nos tergitos 1 e 2 . Fronte (Fig. 18b). Índice frontal 2.6. Face relativamente protuberante. Asa marrom-escura com triângulo interno e borda posterior hialinos (Fig. 44). Espinho antenal 1,5 a 2,0 vezes mais comprido que o pedicelo (Fig. 18a).

Macho: Desconhecido.

Distribuição: Oeste da Colômbia.

Material examinado: S. America, COLOMBIA, Condoto, xii.1914, type, Spheciogaster albomarginatus, $?$, Kroeb., 1929 , pres. by Dr. G.F. Spurrel, B.M. 1916-71, Spheciogaster albomarginata Kroeber, Holotype, J.E. Chainey det., 1978 (flagelo esquerdo ausente, asa direita em microlâmina) (Holótipo 9, BMNH); Chocó, Teresita, 16.v.1967, wing slide made (P, FSCA); 21.xi.1967, 463 (asa esquerda em microlâmina) ( $\mathbf{Q}$, FSCA).

Acanthocera (Nothocanthocera) apicalis Fairchild, comb.n.

(Figs. 19a-c, 45) 
Acanthocera apicalis FAIRCHILD, 1939: 25, Figs. 1, 8, 16 (9);

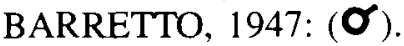

Dichelacera (Nothocanthocera) apicalis; FAIRCHILD, 1969: 209; 1971: 65 (catálogo); WILKERSON, 1981: 67 (em chave).

Diagnose: Tamanho 14,3 - 17,0 $\mathrm{mm}$. Espécie preta com pêlos amarelodourados e pruinosidade amarela na linha sublateral, notopleura, propleura, metepímero, catatergito, anatergito e metade posterior do escutelo. Fronte (Fig. 19b). Índice frontal 3.0. Antena (Fig. 19a) com espinho antenal curvo e longo. Asa (Fig. 45). Pernas distintamente bicoloridas. Abdômen com banda posterior clara nos segmentos 2 e 3. Espécie semelhante morfologicamente a $A$. cnephosa, diferenciando-se principalmente pela presença dos pêlos amarelo-dourados na notopleura e propleura, presença de cinta esbranquiçada na margem posterior do terceiro segmento abdominal.

Macho: Descrito adequadamente por BARRETTO (1947).

Distribuição: Brasil (São Paulo, Paraná).

Material examinado: [BRASIL], São Paulo, Itaporanga, xii.1940, Alótipo (terminália em microlâmina) $(\boldsymbol{\sigma}$, MZUSP); Barão de Antonina, i.1946 (asa direita em microlâmina) ( $\boldsymbol{9}$, MZUSP); Salesópolis, Boracéia, i.1949 ( 9 , MZUSP); 850m, 25.ii.1965, isca humana, $10 \mathrm{~h}$ ( $\boldsymbol{Q}$, MZUSP); 6.xii.1966 ( 9 , MZUSP); 1726.xii.1969 (O, FSCA); Sao Paulo, 29 $\mathrm{Km}, 19-26.1 i .1975$ ( $\boldsymbol{Q}$, FSCA); Paraná, Antonina, 28.ii.1965 ( 9 UFPR); São José dos Pinhais, xii. 1984, na luz (2 $\sigma \sigma$, UFPR); (sem localidade), close to tenuicornis Lutz, but frons narrower ( $\boldsymbol{P}$, FSCA).

Localidade-típica: Säo Paulo, Itaquaquecetuba $(\boldsymbol{Q}, \mathrm{MCZ})$

Acanthocera (Nothocanthocera) cnephosa Barretto, comb.n.

(Figs. 20a-c, 46)

Acanthocera cnephosa BARRETTO, 1947: 99, Figs. 5, 12 (9).

Dichelacera (Nothocanthocera) cnephosa; FAIRCHILD, 1969: 209; PAPAVERO, 1971: 154 (spp.

Barretto); FAIRCHILD, 1971: 66 (catálogo); WILKERSON, 1981:

67 (em chave).

Diagnose: Tamanho 13,0 - 16 $\mathrm{mm}$. Espécie preta com pruinosidade amarela na linha sublateral e dorsalmente no metepímero, pêlos amarelos dorsalmente no anepisterno, borda posterior do escutelo e catatergito. Fronte (Fig. 20b). Índice frontal 2.9. Antena (Fig. 20a) com espinho antenal curvo e longo. Asa (Fig. 46). Pernas fortemente bicoloridas. Abdômen com banda clara nos segmentos 1 e 2 . Espécie semelhante a A. apicalis (ver apicalis).

Macho: Desconhecido.

Distribuição: Brasil (Espírito Santo, Rio de Janeiro).

Material examinado: BRASIL, Rio de Janeiro, Itatiaia, Fazenda Serra, ii.1945, Barretto col. (asa direita em microlamina) (Holotipo $\mathbf{9}$, Paratipo $\mathbf{9}$, MZUSP); Espírito Santo, Santa Tereza, 26.iii.1966 (2 9, UFPR).

Acanthocera (Nothocanthocera) costaricana Fairchild, comb.n.

(Figs. 21a-c, 47) 
Acanthocera costaricana FAIRCHILD, 1941: 647, Fig. 1 (\$); FAIRCHILD \& PHILIP, 1960: 76 (discussão); FAIRCHILD, 1964: 171.

Acanthocera costarricana; FAIRCHILD, 1961c: 26 (grafia incorreta).

Dichelacera (Nothocanthocera) costaricana; FAIRCHILD, 1969: 210; 1971: 66 (catálogo); HOGUE \& FAIRCHILD, 1974: 19 (tab. Costa Rica); WILKERSON, 1981: 67 (em chave).

Diagnose: Tamanho 9,5 - 10,5 mm. Fronte (Fig. 21b). Índice frontal 2.8. Espécie marrom a preta, facilmente distinguível das demais por apresentar: olho não bandeado, palpo delgado (Fig. 21c), linha sublateral amarela incompleta no escudo, antena (fig. 21a), escutelo coberto com pêlos dourados, halter amareloesbranquiçado, pruinosidade cinza-azulada do abdômen restrita ao primeiro tergito. FAIRCHILD (1941), na descrição da espécie, acusa o tamanho do Holótipo ser de $12,0 \mathrm{~mm}$, nosso estudo revelou que o tamanho do espécime é de 10,5 mm.

Macho: Desconhecido.

Distribuição: Honduras, Costa Rica. Material examinado: COSTA RICA, Higuito, San Mateo, Pablo Schild col. (flagelos e palpos ausentes, asa direita em microlâmina) (Holótipo , OSU); HONDURAS, Lancetilla, 9.vii.1954, eye unbanded, wing slide made ( $\boldsymbol{9}$, FSCA).

Acanthocera (Nothocanthocera) diaphorina Barretto, comb.n.

(Figs. 22a-c, 48)

Acanthocera tenuicornis LUTZ, 1915: 63 (part); FAIRCHILD, 1961a: 205 (part).
Acanthocera diaphorina BARRETTO, 1947: 101, Figs. 7, 13 (8).

Dichelacera (Nothocanthocera) diaphorina; FAIRCHILD, 1969: 210; PAPAVERO, 1971: 154 (spp. Barretto); FAIRCHILD, 1971: 66 (catálogo); WILKERSON, 1981: 67 (em chave).

Acanthocera leucotibialis BARRETTO, 1947: 108, Figs. 9, 16 (K).

Dichelacera (Nothocanthocera) leucotibialis; FAIRCHILD, 1969 : 210; PAPAVERO, 1971: 154 (spp. Barretto); FAIRCHILD, 1971: 66 (catálogo); WILKERSON, 1981:65 (como sinônimo de diaphorina).

Diagnose: Tamanho 14,3 - 15,3 $\mathrm{mm}$. Espécie marrom. Linha sublateral amarela. Pêlos pretos na notopleura. Pêlos amarelos esparsos na pleura, mais concentrados póstero-dorsalmente no anepisterno, quarto esclerito alar e borda posterior do escutelo. Fronte (Fig. 22b). Indice frontal 2.7. Pernas fracamente bicoloridas. Antena (Fig. 22a) castanho-amarelada, exceto a metade distal do primeiro flagelômero e anuli mais escuros. Palpo (Fig. 22c) marrom-escuro. Abdômen com banda apical amarela nos segmentos 2 e 3.

Macho: Descrito por BARRETTO (1947) como A. leucotibialis.

Distribuição: Brasil (Minas Gerais, São Paulo, Rio de Janeiro).

Material examinado: [BRASIL. São Paulo], Poço Preto, ii.1936. Acanthocera diaphorina, n.sp. Barretto. Holótipo (asa direita em microlâmina) (Holótipo 9, MZUSP); Alto da Serra, xii.1935, Worontzow col. (Parátipo ?. MZUSP); Ipiranga, iii.1937, R. Spitz 
col. (Parátipo $\mathbf{8}$, MZUSP); Minas Gerais, Pacau, ii.1912, NT 368, Inst. O. Cruz, A. Lutz col. (asa esquerda em microlâmina) (Lectótipo \$, Acanthocera tenuicomis, designado erroneamente por FAIRCHILD, 1961, FIOC); NT 367 (Paralectótipo $\mathbf{Q}$, A. tenuicornis, designado erroneamente por FAIRCHILD, 1961, FIOC); Rio de Janeiro, Itatiaia, Fazenda Serra, ii.1945, Barretto col. (Holótipo $\boldsymbol{\sigma}$, Acanthocera leucotibialis, MZUSP).

\section{Acanthocera (Nothocanthocera)} distincta, sp. n.

(Figs. 23a-c, 49)

Diagnose: Espécie marrom. Tamanho 10,0 - 11,1 mm. Tergitos $1 \mathrm{e}$ 2 semi-transparentes, com mancha escura medianamente no dorso e margem anterior do segundo segmento. Escudo com duas linhas douradas longitudinais em toda sua extensão. Asa marrom na margem anterior, células $r 2+3, r l$ e cup, o restante hialino.

Fêmea: Tamanho 10,6 mm. Asa $9,6 \mathrm{~mm}$. Indice frontal 3.0. Olhos glabros. Fronte (Fig. 23b) com calo marrom a preto, nítido vestígio de ocelos no tubérculo ocelar. Subcalo concolor com pruinosidade amarela. Antena (Fig. 23a) com escapo, pedicelo e base do primeiro flagelômero, inclusive o espinho, marrom-claro, o restante marrom a preto. Face marrom, brilhante, com pruinosidade amarela abaixo da fosseta tentorial. Parafaciália e gena cobertas de pruinosidade amarela. Palpo (Fig. 23c) marromclaro com pêlos pretos e alguns amarelos na base do segundo segmento. Tórax com escudo marromescuro, duas faixas longitudinais com pruinosidade e pêlos dourados. Notopleura amarelada com pêlos dourados. Pleura amarelada com pruinosidade e pêlos amarelos, exceto metade anterior do anepisterno, marrom. Escutelo marrom no 1/3 anterior, o restante marrom-amarelado. Asa (Fig. 49) marrom na margem anterior incluindo a célula $r 2+3$, célula $r 1$ mais clara, célula cup marrom-clara, o restante hialino. Halter amarelo-creme. Pernas amarelas com pêlos amarelos, exceto $1 / 2$ basal da tíbia anterior, $4 / 5$ basais da tíbia média e $1 / 2$ basal da tíbia posterior, brancos com pêlos da mesma cor. Abdômen marrom, tergitos 1 e 2 semi-transparentes com tegumento mais escuro medianamente no dorso e margem anterior do segundo segmento. Cobertura pilosa do abdômen marrom, exceto por pêlos amarelos dorsalmente no primeiro segmento, borda posterior do segundo, esparsos no quinto e mais numerosos no sexto e sétimo segmentos.

Macho: Desconhecido.

Material examinado: BRASIL, Amazonas, São Gabriel da Cachoeira, Morro dos Seis Lagos, $800 \mathrm{~m}$, 28.ix.1990, Armadilha suspensa, J. A. Rafael \& J. Vidal cols. (Holótipo ?, INPA; 4 Parátipos $\mathbf{9}$ (2 INPA, 1 MPEG, 1 MZUSP).

Discussão: Espécie facilmente distinguível das demais por apresentar: corpo marrom-amarelado e os dois primeiros tergitos semi-transparentes.

Acanthocera (Nothocanthocera) flavicosta (Wilkerson), comb. n. 
Dichelacera (Nothocanthocera) flavicosta WILKERSON, 1981: 63, Figs. 2a-c, 5 (9).

Comentários: Não vimos o Holótipo, único exemplar desta espécie, depositado no Zoologische Staatsammlung, Munique, Alemanha, por impedimento de empréstimo. A descrição e figuras de Wilkerson são adequadas para o enquadramento em Acanthocera (Nothocanthocera).

Diagnose: Tamanho 14,0 mm. Indice frontal 2.9. Espécie marromescura com face lisa, brilhante. Espinho antenal relativamente longo, delgado. Palpo sub-brilhante, um pouco inflado na base. Asa tricolorida, largamente amarela ao longo da margem anterior, marrom ao longo da veia R5 até a forquilha, ao longo da veia $\mathrm{R} 4$ e $1 / 2$ apical da célula cup, o restante hialino.

Macho: Desconhecido.

Distribuição: Venezuela (Bolivar).

Acanthocera (Nothocanthocera) nigricorpus Lutz, comb.n.

(Figs.24a-c, 50)

Acanthocera nigricorpus LUTZ, 1915: 64, Pr. 19, Fig. 7 ( 9 ); ENDERLEIN, 1925: 333 (distribuição); KROEBER, 1928: 92 (redescrição); 1934: 254 (catálogo); FAIRCHILD, 1939: 21 (revisão); BARRETTO, 1947: 96, Fig. $3(\boldsymbol{\sigma})$; FAIRCHILD, 1961a: 204 (spp. Lutz).

Dichelacera (Nothocanthocera) nigricorpus; FAIRCHILD, 1969: 210; 1971: 66 (catálogo); WILKERSON, 1981: 65 (em chave).
Diagnose: Tamanho 15,0 - 17,7 $\mathrm{mm}$. Espécie preta. Asa amarela, sem áreas hialinas (Fig. 50). Índice frontal 2.6. Antena (Fig. 24a) com espinho antenal longo e curvo.

Macho: Descrito adequadamente por BARRETTO (1947).

Distribuição: Brasil (Rio de Janeiro, São Paulo, Santa Catarina, Rio Grande do Sul).

Material examinado: [BRASIL, Santa Catarina], Joinvile, NT 364 , coleção A. Lutz (antenas e asa direita ausentes) (Holótipo P, FIOC); São Paulo, Cidade Jardim, 20.ii.1943 (terminália em microlâmina) ( $\boldsymbol{\sigma}$, MZUSP); Osasco, 1952 (\$, MZUSP); Rio de Janeiro, Represa Rio Grande, xi.I966 (espécime danificado) (\$, MNRJ); Rio Grande do Sul, São leopoldo, 10.vi.1965 (asa direita em microlâmina) ( $\mathbf{Q}$, MZUSP).

Acanthocera (Nothocanthocera) steleiothorax Barretto, comb.n. (Figs. 25a-b, 51)

Acanthocera steleiothorax BARRETTO, 1947: 106, Figs. 8, $15(\boldsymbol{\sigma})$.

Dichelacera (Nothocanthocera) steleiothorax; FAIRCHILD, 1969: 210; 1971: 66 (catálogo); WILKERSON, 1981: 66 (em chave).

Diagnose: Tamanho 14,0 mm. Espinho antenal (Fig. 25a), quase reto, com ápice distante da base do primeiro anulus. Asa (Fig. 51). Tórax com tufos de pêlos amarelos na pleura. Linha sublateral amarela com pêlos amarelos. Abdômen marrom, exceto os tergitos 1 e 2 mais claros.

Fêmea: Desconhecida. 
Distribuição: Brasil (Paraná).

Material examinado: [BRASIL], Paraná, Campo Largo, Rio Papagaios, iii.1945, Hatschabach col. (bem preservado, terminália e asa direita em microlâminas) (Holótipo $\boldsymbol{\sigma}$, MZUSP).

Acanthocera (Nothocanthocera) tenuicornis Lutz, comb.n.

(Figs. 26a-c, 52)

Acanthocera tenuicornis LUTZ, 1915: 63, Pr. 19, Fig. 6 ( 9 ) part.; ENDERLEIN, 1925: 333 (distribuição); KROEBER, 1928: 85 (redescrição); 1934: 254 (catálogo); FAIRCHILD, 1939: 24 (revisão); BARRETTO, 1947: 92 $(\boldsymbol{\sigma})$; FAIRCHILD, 1961a: 205 (desig. Lectótipo e Paralectótipos, part.).

Dichelacera

(Nothocanthocera) tenuicornis; FAIRCHILD, 1969: 209; 1971: 66 (catálogo); WILKERSON, 1981: 66 (em chave).

Diagnose: Tamanho 13,0 - 15,5 $\mathrm{mm}$. Espécie marrom-clara com tufos de pêlos amarelos localizados lateralmente no tórax, duas linhas amarelas, curtas longitudinais no escudo. Asa (Fig. 52) com enfuscação oblíqua, de intensidade variável, ligando a enfuscação da margem anterior com a da célula cup. Espinho antenal (Fig. 26a) quase reto, ápice distante da base do primeiro anulus. Fronte (Fig. 26b). Índice frontal 2.8. Abdômen com banda apical amarela nos tergitos 1-6.

Macho:'Descrito adequadamente por BARRETTO (1947).

Distribuição: Brasil (Minas Gerais, São Paulo, Paraná, Santa
Catarina)

Material examinado: Lectótipo 9 , PRESENTE DESIGNAÇÃO: [BRASIL, São Paulo], Piassaguera, 25.x.1906, Acanthocera tenuicornis LUTZ, 1915, Paratype (sic), 1252 (Lectótipo 9, FIOC); (152 99 e 26 o $\sigma$, MZUSP; 2 9 e 1 \%, MPEG; 3 ९९, UFPR, 3 ९९, FSCA).

FAIRCHILD (1961a) designou o Lectótipo e dois Paralectótipos para A. tenuicornis. A análise desses espécimes revelou que o Lectótipo e um Paralectótipo não pertencem a tenuicornis e sim a Acanthocera diaphorina, com base nos seguintes caracteres: ausência da enfuscação oblíqua na asa, antena robusta, presença de pêlos pretos na notopleura e abdômen com apenas duas bandas amarelas, que são características de diaphorina. Com base na designação errônea de Fairchild, designamos como Lectótipo de tenuicornis o outro Paralectótipo (ver material examinado).

Acanthocera (Nothocanthocera) trigonifera Schiner, comb.n.

(Figs. 27a-c, 53)

Acanthocera trigonifera SCHINER, 1868: 95 (\$); KERTÉSZ, 1900 : 29 (catálogo); HUNTER, 1901 : 138 (catálogo); RICARDO, 1904: 264; SURCOUF \& GONZ A LES - R INCONES, 1912: 53; LUTZ, 1915: 62 (trad descrição original); SURCOUF, 1921: 90; ENDERLEIN, 1925: 333; LUTZ, 1928: 56 (tab. Venezuela); KROEBER, 1928: 89 (determinação errônea); 1934: 254 (catálogo); FAIRCHILD, 
1939: 21 (revisão); 1967b: 251 (spp. Schiner).

Dichelacera (Nothocanthocera) trigonifera; FAIRCHILD, 1969:

210; 1971: 66 (catálogo); WILKERSON, 1981: 66 (em chave).

Diagnose: Tamanho 9,0 - 10,0 mm. Fronte (Fig. 27b). Índice frontal 2.3. Espinho antenal curto (Fig. 27a), escapo e pedicelo amarelos, último anulus tão longo quanto largo. Asa (Fig. 53) marrom com área hialina triangular no meio, próximo a base e borda posterior. Abdômen com nítido triângulo marrom a preto no tergito 2 . Escudo com duas linhas sublaterais amarelas.

Macho: Desconhecido.

Distribuição: Oeste da Venezuela e Colômbia.

Material examinado: COLOMBIA, 1925, Mac. Pehlke \& E. Pehlke cols., Spheciogaster albomarginatus Kroeb., det. Kroeber, 1930, wing slide made, Mus. Zool. Polonicum, Werszawa, 12, 43 ( $\boldsymbol{9}$, FSCA); Rio magdalena, Pehlke col. (asa direita em microlâmina) ( $\mathbf{Q}$, MPEG).

Observação: Síntipos, não observados, depositados no Naturhistorisches Museum, Viena, Áustria.

\section{Subgênero Polistimima Fairchild}

Acanthocera (Polistimima) FAIRCHILD, 1969: 209; 1971: 60 (catálogo).

Espácièipo Acanthocera

polistiformis Fairchild (mon.).

Diagnose: Subgênero monotí- pico caracterizado pelo aspecto vespiforme semelhante a representantes do gênero Polistes (Hymenoptera: Vespidae). Escapo e pedicelo juntos maior que o flagelo e labela mais esclerotinizada que as demais espécies do gênero.

Acanthocera (Polistimima) polistiformis Fairchild

(Figs. 28a-d, 54)

Acanthocera polistiformis FAIRCHILD, 1961b: 436, Fig. 1 (O).

Acanthocera Polistimima) polistiformis;

FAIRCHILD, 1969: 209; 1971: 60

(catálogo).

Diagnose: Tamanho 16,0 mm. Corpo amarelo-avermelhado. Asa marrom. Palpo extremamente inflado. Acanthocera polistiformis apenas conhecida do Holótipo macho do Estado do Amapá. Recentemente a fêmea foi coletada próximo à Manaus, Amazonas, que descrevemos a seguir.

Descriçäo da fêmea: Tamanho: $16,0 \mathrm{~mm}$. Índice frontal 1.6. Olhos glabros. Fronte (Fig. 28b) marrom a preta, brilhante, apenas vestígios de ocelos próximo ao vértice. Calo frontal mais estreito que a fronte, com depressão na porção mediana. Subcalo amarelado com pruinosidade acinzentada. Antena (Fig. 28a) com escapo amarelo- avermelhado, pedicelo mais escuro, flagelo marrom a preto. Primeiro flagelômero com espinho dorsal longo. Face, parafaciália e gena amarelo-avermelhadas com faixas de pruinosidade cinza- amarelada. Palpo (Fig. 28c) extremamente inflado, amarelo- avermelhado com pêlos curtos, marrons. Labela esclerotiniza- 
da. Tórax amarelo-avermelhado exceto o escudo, região póstero-dorsal do anepisterno e catatergito marrons; revestimento piloso laranja. Pernas amarelo-avermelhadas com pêlos alaranjados. Asa (Fig. 54, do Holótipo) marrom, venação normal. Halter marrom com haste amarelada. Abdômen amarelo-avermelhado com pêlos alaranjados. Tergitos 1 e 2 e esternito 2 com banda apical estreita com pruinosidade e pêlos brancos. Constrição no abdômen ao nível do segundo e terceiro segmentos.

Distribuição: Brasil (Amapá, Amazonas).

Material examinado: BRASIL, Amapá, 18.ix.1957, J. Lane leg. Holotype (bem preservado, asa esquerda montada em microlâmina, asa direita com borda anterior danificada) (Holótipo $\boldsymbol{\sigma}$, MZUSP); BRASIL, Amazonas, $\pm 60 \mathrm{Km} \mathrm{N}$. Manaus, 25.ix.1985, Armadilha Malaise, B. Klein col. (espécime previamente fixado em álcool, borda das asas danificadas) ( $\mathbf{9}$, INPA).

Discussão: O exame do exemplar fêmea demonstrou pertencer a espécie descrita por Fairchild. Entretanto, a presença do espinho antenal nesta, nos forçou a formular as hipóteses de dimorfismo sexual ou mais provavelmente de uma falha genética no macho, pois não há resquícios de quebra na protuberância do primeiro flagelômero deste (Fig. 28d).

\section{AGRADECIMENTOS}

Aos curadores e instituições que gentilmente cederam espécimes para estudo. Ao Conselho Nacional de Desenvolvimento Científico e Tecnológico-CNPq, que tem apoiado nossa carreira científica desde o início. A Sra. Ana Maria de Oliveira, Museu Paraense Emílio Goeldi-MPEG, pelo auxílio na normatização da bibliografía citada.

\section{Bibliografia citada}

BARRETTO, M.P. 1947. Estudos sobre tabânidas brasileiros IV. Sobre o gênero Acanthocera Macq., 1834, com as descriçōes de cinco novas espécies (Diptera:Tabanidae). An. Fac. Med. Univ. São Paulo, 23: 89-115.

1960. Chave para os gêneros neotropicais de tabânidas (Diptera: Tabanidae). Pap. Avulsos Dep. Zool., 14 (7): 57-69.

BEQUAERT, J. 1926. Medical report of the Hamilton Rice seventh expedition to the Amazon, in conjunction with the departament of Tropical Medicine of Harvard University, 1924-1925. Part 2. Medical and Economic entomology, Contr. Harv. Inst. Trop. Biol. Med., Cambridge, 4: 15-257.

1944. Further studies of the Tabanidae of Trinidad, B.W.I., Psyche, 51 (1/2): 12-21.

BORGMEIER, T. 1933. A propósito da nomenclatura dos Tabanidae da região neotrópica. Rev. Ent., Rio de Janeiro, 3 (3): 286-303.

BOUVIER, G. 1952. Notes sur les tabanidés de la region de Campinas (Estado de S. Paulo)-Brésil. Mem. Inst. Oswaldo Cruz, Rio de Janeiro, 50: 580-596.

BRÈTHES, J. 1921. Los Tabanidos del Plata. Estudios, 21(3): 1-79.

COSCARÓN, S. 1966. Algunos tábanos nuevos para la fauna argentina (Insecta: Diptera). Revta. Soc. Ent. Argent., 28 (1/4): 57-59.

1967. Elenco sistematico de Tabanidae argentina Diptera: Insecta). Seg. Entomoepid. Argent., 1: 105-131. 
1978. Notas sobre tabanidos argentinos XVII. Los generos Phaeotabanus Lutz y Acanthocera Macq. en la Argentina (Tabanidae:Diptera). Revta Soc, ent. Argent., 37 (1/4): 27-32.

ENDERLEIN, G. 1922. Ein neue Tabanidensystem. Mitt. Zool. Mus. Berlin, 10 (2): 333-351.

1925. Studien an blutsaugenden Insekten I. Grundlagen eines neuen Systems der Tabaniden. Mitt. Zool. Mus. Berlin, 11 (2): 255-409.

FABRICIUS, J.C. 1775. Systema entomologia, sistens insectorum classes, ordines, genera, species adiects synonymis, locis, descriptionibus, observationibus. 832 pp.Flensburg and Leipzig.

1805. Systema autliatorum secudum ordines, genera, species. $373+30 \mathrm{pp}$. Brunsvigae (=Brunswick)

FAIRCHILD, G.B. 1939. Notes on the genus Acanthocera Macq. (Diptera: Tabanidae). Rev. Ent., Rio de Janeiro, 10 (1): 1427. 1941. A new Acanthocera (Diptera: Tabanidae) from Central America. Ann. Ent. Soc. Am., 34 (3): 647-648.

1961a. The Adolpho Lutz collection of Tabanidae. I. The described genera and species, condition of the collection, and selection of lectotypes. Mem. Inst. Oswaldo Cruz, 59 (2): 185-249.

1961b.Insecta Amapaensia Diptera: Tabanidae. Studia Ent., 4 (1-4): 433448.

1961c. A preliminary check list of Tabanidae (Diptera) of Costa Rica. Rev. Biol. Trop., 9 (1): 23-38.

1964. Notes on Neotropical Tabanidae (Diptera). IV. Further new species and new records for Panama. J. Med. Ent., 1 (2): 169-185.

1966a. Notes on Neotropical Tabanidae (Diptera). V. The species described by Enderlein. J. Med. Ent., 3 (1): 1- 19.

1966b. Notes on Neotropical Tabanidae (Diptera). VIII. The species described by J.C.Fabricius. Psyche, 73 (1): 17-25. 1966c. Notes on Neotropical Tabanidae (Diptera) IX. The species described by Otto Kroeber. Studia Ent., 9 (1-4): 329-383.

1967a. Notes on Neotropical Tabanidae (Diptera) VII. The species described by C.R. Wiedemann. Pacif. Insects, 9 (1): 73-104.

1967b. Notes on Neotropical Tabanidae (Diptera). X. The species described by J. R. Schiner and others. Pacif. Insects, 9 (2): 243-256.

1969. Notes on Neotropical Tabanidae (Diptera) XII. Classification and distribution, with keys to genera and subgenera. Arq. Zool. São Paulo, 17 (4): 199-255.

1971. A catalogue of the Diptera of the Americas south of the United States. Family Tabanidae. 28. Museu Zoologia/ USP, 163p.

1975. Notes on Neotropical Tabanidae (Diptera) XV. Some species described by $\mathrm{O}$. Kroeber formerly in the Stettin Museum. Proc. ent. Soc. Wash., 77 (2): 258-265.

1985. Notes on Neotropical Tabanidae (Diptera). XV1ll. The Genus Leucotabanus Lutz. Myia, 3: 299-331.

FAIRCHILD, G.B. \& AITKEN, G.H.E. 1960. Additions to the Tabanidae Soc. Am. 53 (1): $1-8$.

FAIRCHILD, G.B. \& PHILIP, C.B. 1960. A Revision of the Neotropical Genus Dichelacera Subgenus Dichelacera, Macquart (Diptera: Tabanidae). Studia Ent., 3 (1-4): 1-96.

FISCHER, R. 1939. O macho de Acanthocera coarctata (Wied) (Diptera: Tabanidae). Rev. Ent., Rio de Janeiro, 10 (2): 334-337.

HENRIQUES, A.L. \& RAFAEL, J.A. 1992. Notes on the Neotropical genus Acanthocera Macquart (Diptera: Tabanidae) with description of four new species. Goeldiana Zool., Belém, (13): 1-13.

HOGUE, C.L. \& FAIRCHILD, G.B. 1974. A revised check list of the Tabanidae (Diptera) of Costa Rica. Rev. Biol. Trop., 22 (1): 11-27. 
HUNTER, W. D. 1901. A catalogue of the Diptera of South America, Part 2. Trans. Am. ent. Soc., 27: 136-147.

KERTÉSZ, K. 1900. Catalogus tabanidorum orbis terrarum universi. Budapest, $78 \mathrm{p}$.

KROEBER, O. 1928. Die amerikanischen Arten der Tabaniden - Subfamilie Diachlorinae End. Archiv. Schiffo-und Ther. Exot. Krank., 32 (2): 1-55.

1930. Neue Tabaniden und Zuzatze zu bereits Beschriebenen. Zool. Anz., 90: 69-86.

1934. Catálogo dos Tabanidae da América do Sul e Central, incluindo o México e as Antilhas. Rev. Ent., 4 (2): 222-276.

LUTZ, A. 1915. Tabanidas do Brasil e alguns estados vizinhos. Segunda Memória. Mem. Inst. Oswaldo Cruz, 7 (1): 51-119. 1928. Estudios de Zoologia y Parasitologia Venezoelanas, Rio de Janeiro, 133p.

MACQUART, J. 1834. Histoire naturelle des Insectes. Diptères 1:in: Roret, N.E. (ed.), collection des suites à Buffon, 578p.

1838. Diptères exotiques nouveaux ou peu connus. Mém. Soc. Roy. Sci, l'Agr. Arts Lille, Paris, (2): 9-225.

McALPINE, J.F. 1981. Morphology and terminology. Adults. in: McAlpine, J.F. et al. (eds.), Manual of Neantic Diptera, p. 9-63. (Monograph 27).

PAPAVERO, N. 1971. On Prof.Mauro Pereira Barretto's collection of tabanidae types. Pap. Avul. Zool., 23 (17): 153-156.

RAFAEL, J.A. \& GORAYEB, I.S. 1982. Tabanidae (Diptera) da amazônia. 1. Uma nova armadilha suspensa $\mathrm{e}$ primeiros registros de mutucas de copas de árvores. Acta Amazonica, Manaus, 12 (1): 232-236.
RICARDO, G. 1904. Notes on the smaller genera of the Tabaninae of the family Tabanidae in the British Museum Collection. Ann. Mag. Nat. Hist, 14 (7): 349-373.

SCHINER, J.R. 1866. Bericht über die von Weltumseglungsreise der K. Fregate Novara mitgebrachten Dipteren. Verh. Zool. bot. Ges. Wien., 16: 303-314.

1868. Reise der Österreichischen Fregatte Novara un die Erde., Viena, Zool. Theil. 2(1,B) (Diptera), 388p.

STRICKMAN, D. 1982. Notes on Tabanidae (Diptera) from Paraguay. J. Med. Ent. , 19 (4): 399-402.

SURCOUF, J.M.R. 1921. Fam. Tabanidae, in Wytsman, P. (ed.), Genera Insectorum, p. $175,1-182$.

SURCOUF, J. M. R. \& GONZALESRINCONES, R. 1912. Essai sur les diptères vulnerantes de Venezuela. Matériaux pour servir à l'étude des diptères piqueurs et suceurs de sang de l'A mérique intertropicale. Deuxième partie. Diptères brachyceres vulnerants, Paris, A. Maloine, p. 1-240.

WALKER, F. 1854. List of the specimens of dipterous insects in the collection of the British Museum. Londres, 5 (suppl.1): 1-330, 6 (supll.2): 331-506.

WIEDEMANN, C. R. W. 1828. Asseneuropäische zweiflügelike Insekten, 1: 608p.

WILKERSON, R.C. 1979. Horse flies (Diptera: Tabanidae) of the Colombian departaments of Choco, Valle, and Cauca. Cespedesia, 8 (32): 99-430.

1981. Two new species of Dichelacera (Nothocanthocera) Fairchild with a key to the species of the subgenus (Diptera:Tabanidae). Proc. ent. Soc. Wash., 83 (1): 64- 71. 

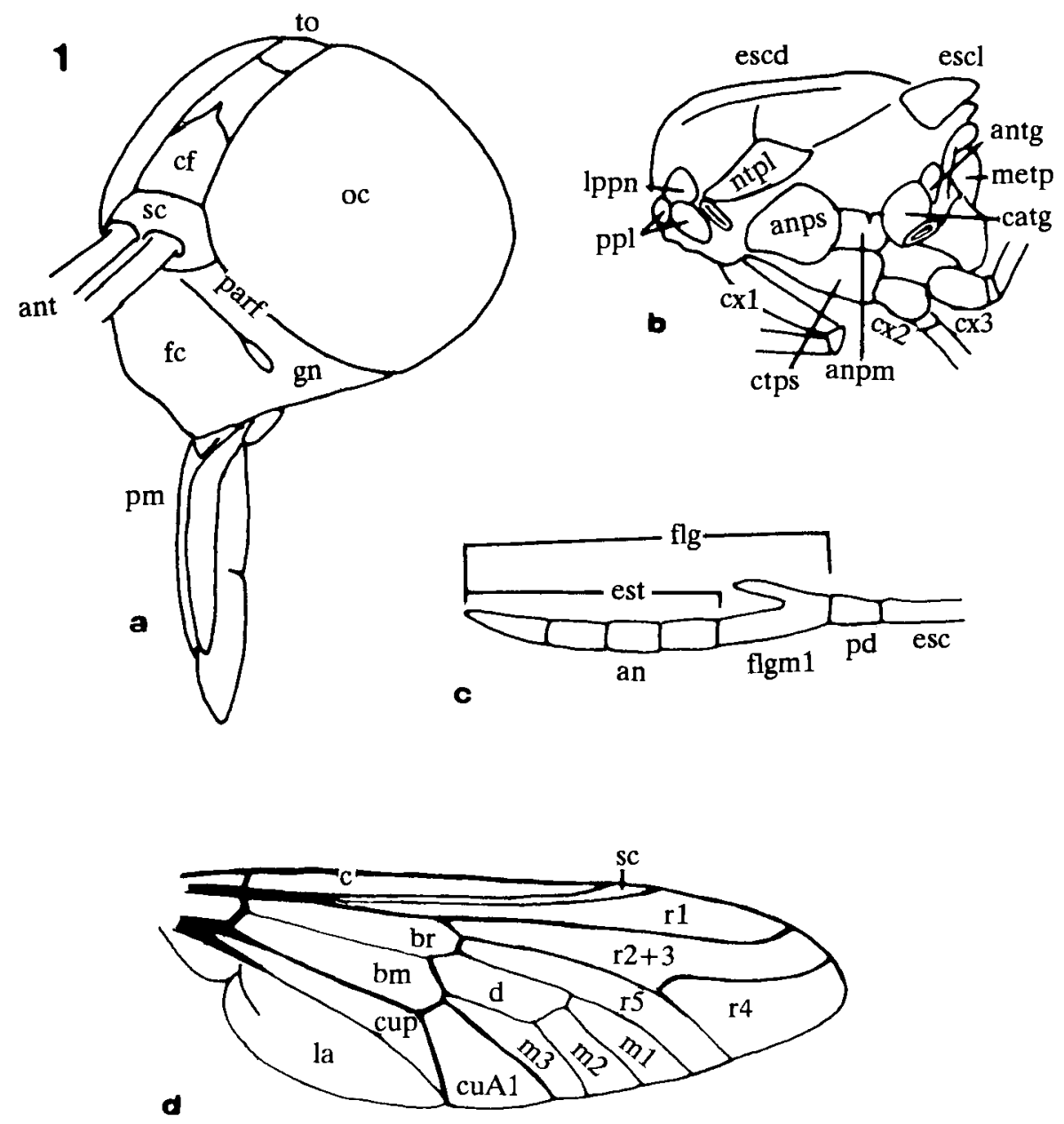

Figura 1. Terminologia morfológica. a). Cabeça: ant, antena; cf, calo frontal; fc, face; gn, gena; parf, parafaciália; pm, palpo maxilar; oc, olho composto; sc, subcalo; to, tubérculo ocelar; b). Tórax, vista lateral; anpm, anepímero; anps, anepisterno; antg, anatergito; catg, catatergito; ctps, catepisterno; cx 1, coxa 1; cx2, coxa 2; cx3, coxa 3; escd, escudo; escl, escutelo; lppn, lobo pós-pronotal; metp, metepímero, ntpl, notopleura; ppl, propleura; c). Antena: an, anulus; esc, escapo; est, estilo; flg, flagelo; flgm I, primeiro flagelômero; pd, pedicelo; d). A sa, células: bm, basal-medial; br, basal-radial; c, costal; cuA l, cúbito-anal 1; cup, cubital-posterior; d, discal; la, lobo anal; $\mathrm{m} 1$, medial $1 ; \mathrm{m} 2$, medial $2 ; \mathrm{m} 3$, medial $3 ; \mathrm{rl}$, radial $1 ; \mathrm{r} 2+3$, radial $2+3 ; \mathrm{r} 4$. radial $4 ; r 5$, radial $5 ; \mathrm{sc}$, subcostal. 


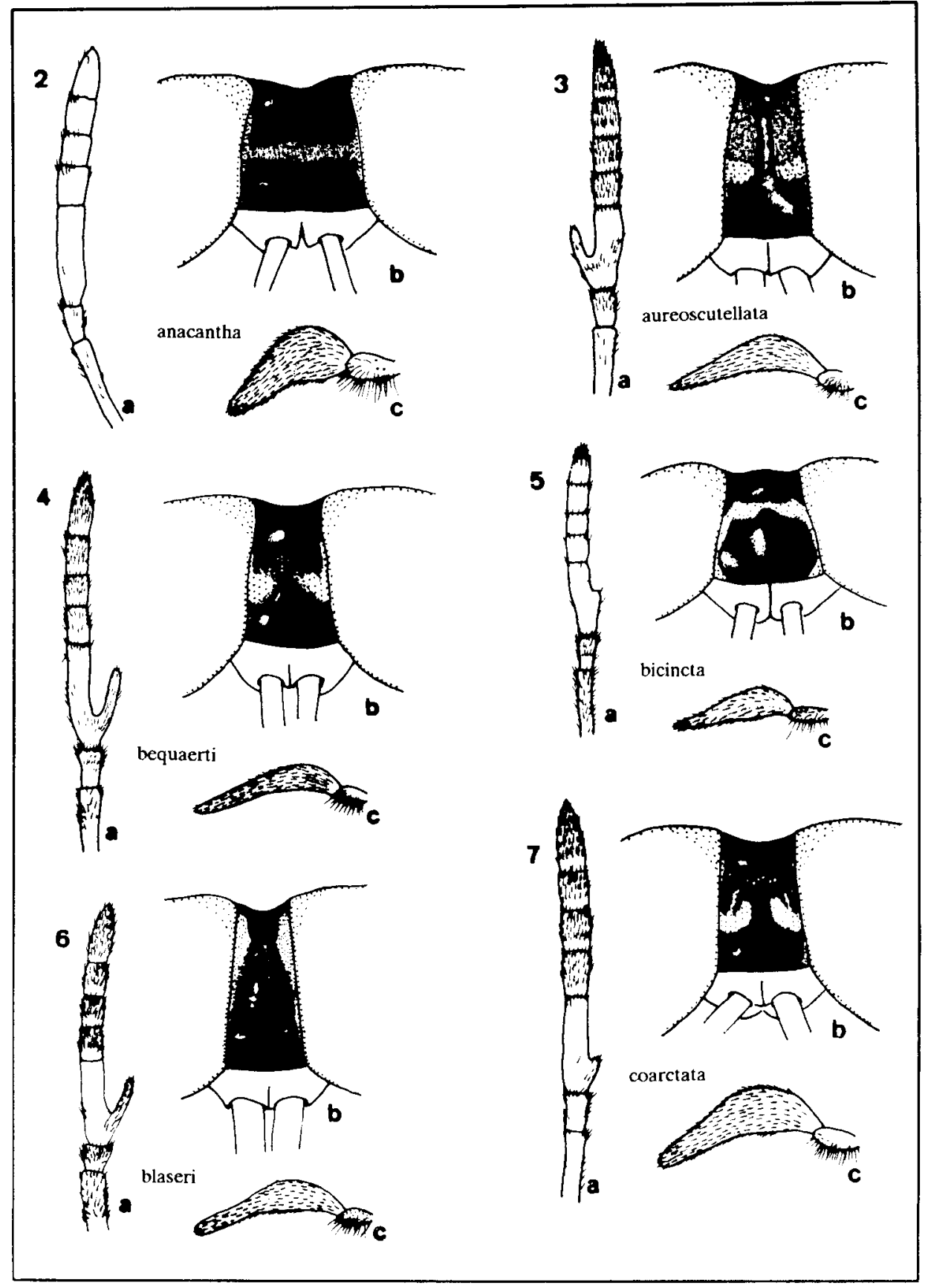

Figuras 2-7: a, antena; b, fronte; c, palpo. 2, A. anacantha, Lectótipo; 3, A. aureoscutellata, Holótipo; 4, A. bequaerti, Parátipo fêmea; 5, A. bicincta, Holótipo; 6, A. blaseri, Holótipo; 7 , $A$. coarctala, fêmea. 


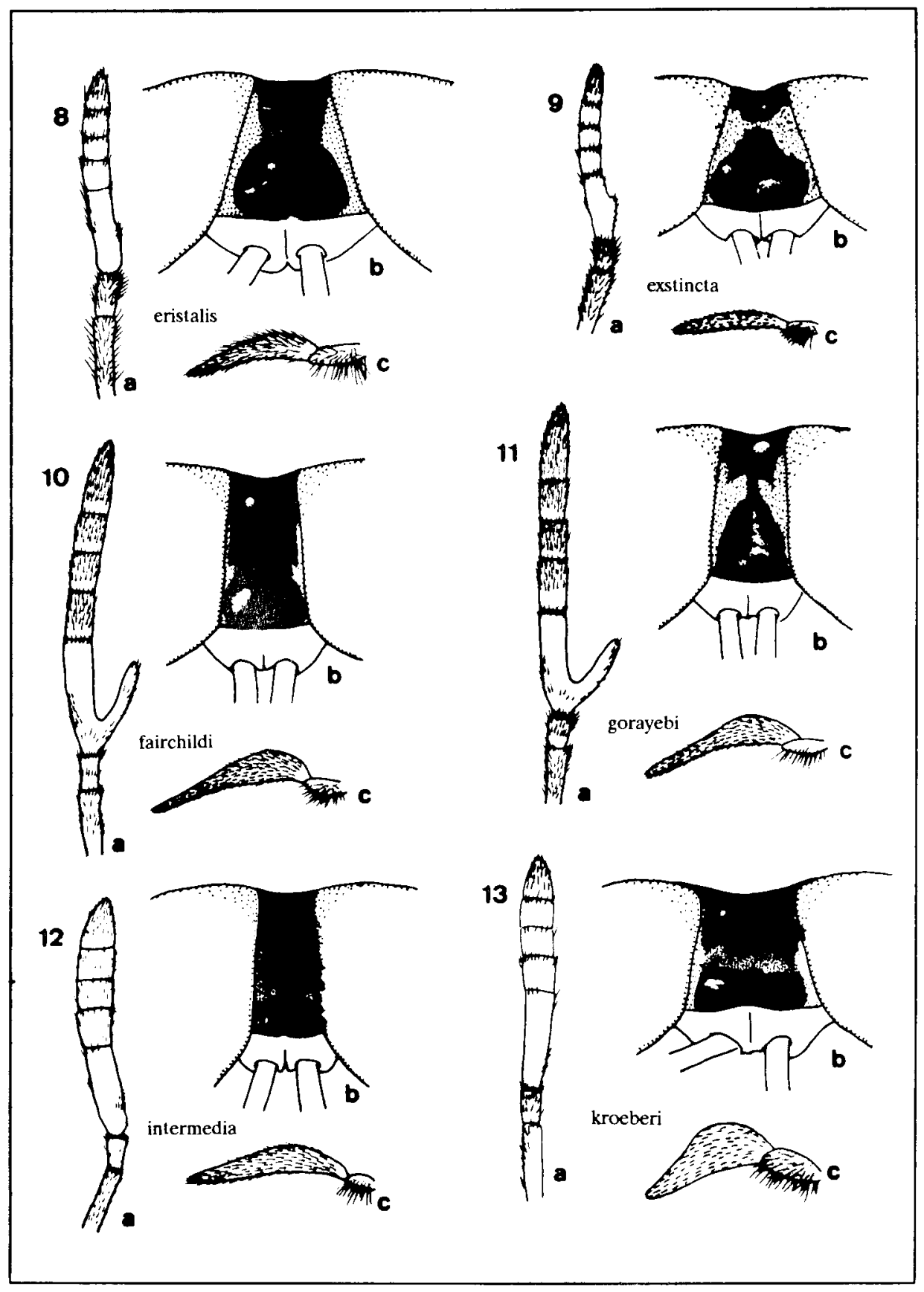

Figuras 8-13: a, antena: b, fronte; c, palpo; 8, A. eristalis, Holótipo: 9, A exstincta, fêmea; 10, A. fairchildi, Parátipo fêmea; 11, A. gorayebi, Holótipo; 12, A. intermedila, a, Paralectótipo fêmea, vista dorsal, b e c, Lectótipo; 13, A. kroeberi, Holótipo. 


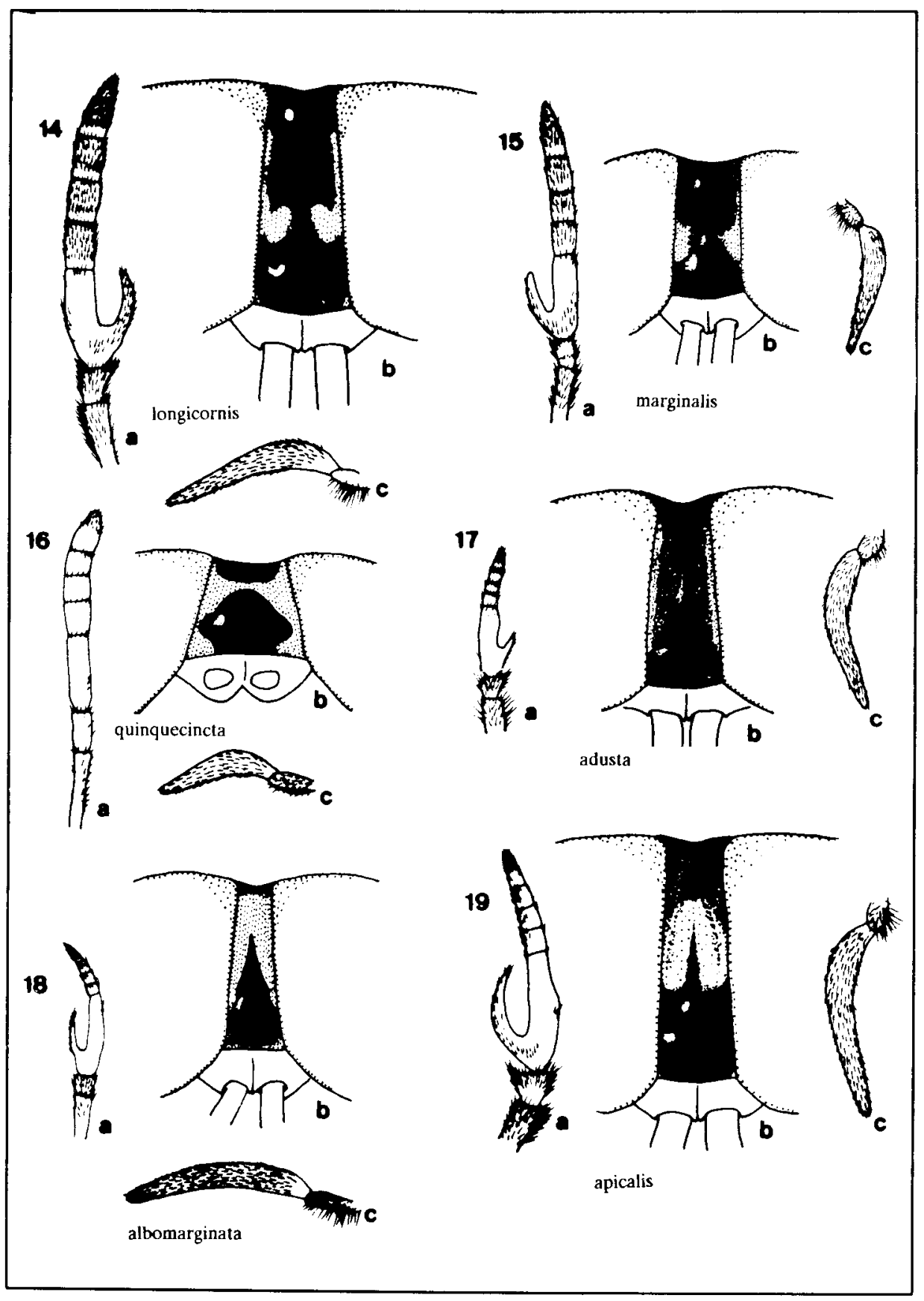

Figuras 14-19: a, antena; b, fronte; c, palpo. 14, A. longicornis, fêmea; 15, A. marginalis, Holótipo; 16, A. quinquecincta, Lectótipo; 17, A. adusta, Parátipo fêmea; 18, A. albomarginata, Holótipo; 19, A. apicalis, fêmea. 

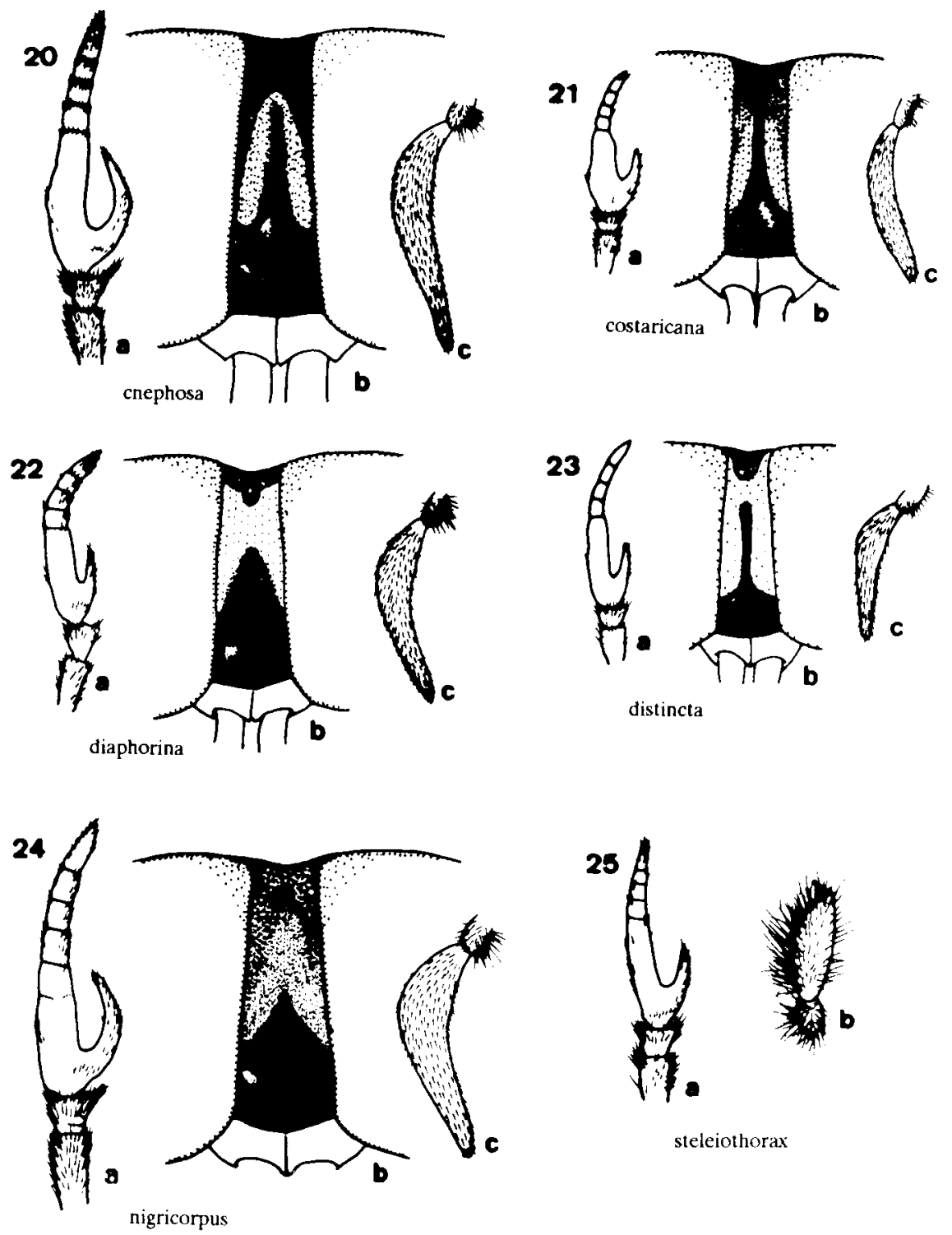

steleiothorax distincta

Figuras 20-25: a, antena; b, fronte; c, palpo. 20, A. cnephosa, Holótipo; 21, A. costaricana fêmea; 22, A. diaphorina, Holótipo; 23, A. distincta, sp. n., Holótipo; 24, A. nigricorpus. Holótipo; 25, A. steleiothorax, Holótipo (antena e palpo). 


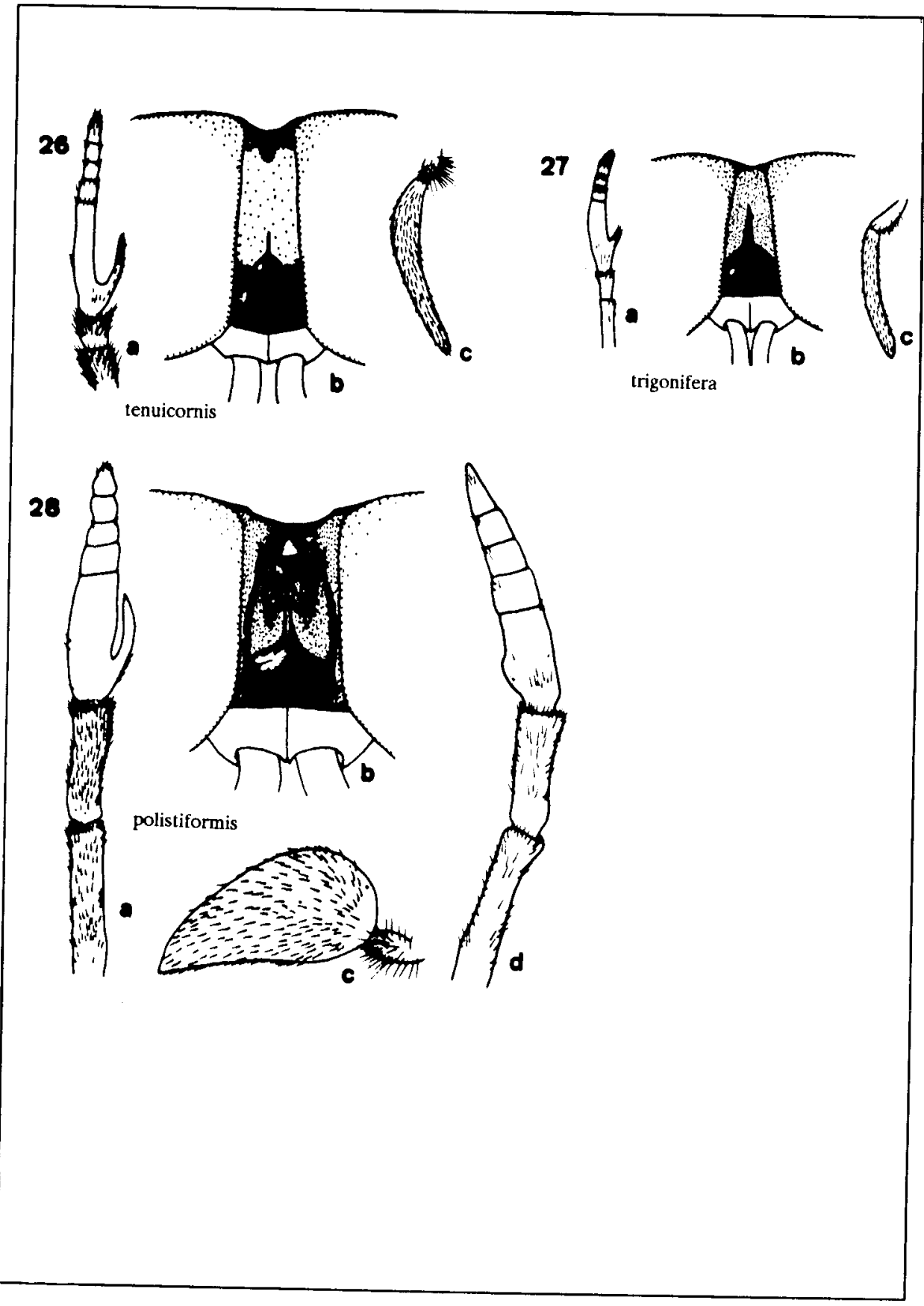

Figuras 26-28: a, antena; b, fronte; c, palpo. 26, A. tenuicornis, Lectótipo fêmea; 27, A. trigonifera, fêmea; $\mathbf{2 8}$, A. polistiformis, a-c, fêmea, d, antena direita do Holótipo macho. 
29

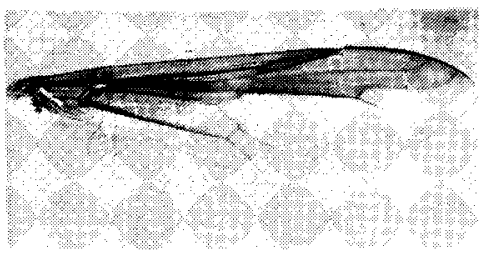

anacantha

31

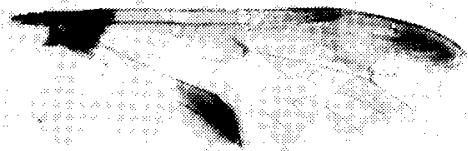

bequaerti

33

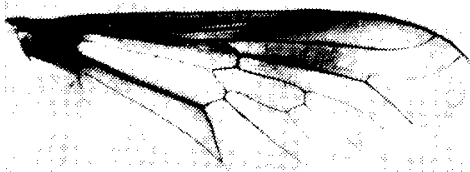

blaseri

35

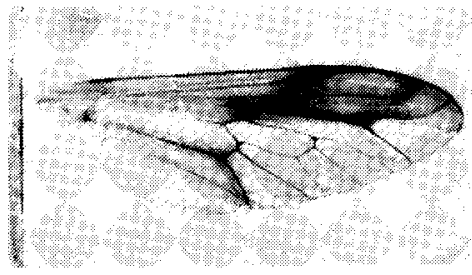

eristalis

37

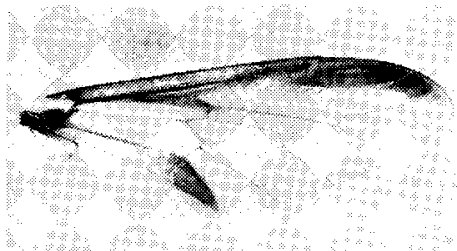

fairchildi
30

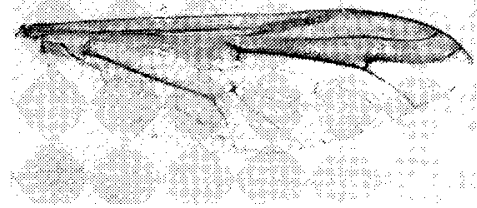

aureoscutellata
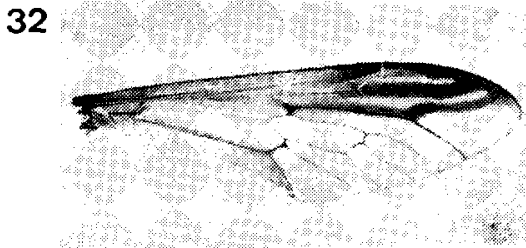

bicincta

34

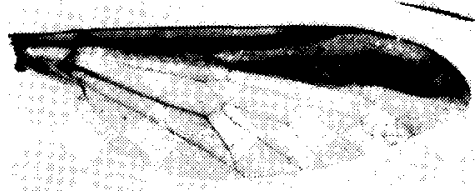

coarctata

36

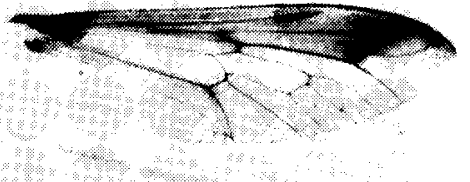

exstincta

38

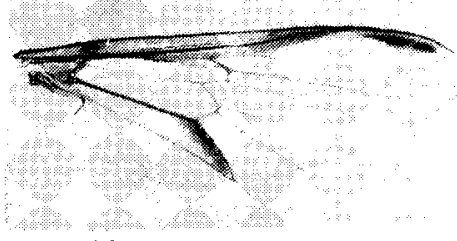

gorayebi

Figuras 29-38: asas. 29, A anacantha, fêmea; 30, A. aureosscuic llùu, Pùrátipo fêmea; $31, A$ bequaerti, Parátipo fêmea; 32, A. bicincta, Parátipo fêmea; 33, A. blaseri, Holótipo; 34, A. coarctata, Holótipo; 35, A. eristalis, Holótipo; 36, A. exstincia, fêmea; 37, A fairchildi, Parátipo fêmea; 38, A. gorayebi, Parátipo fêmea. 
39

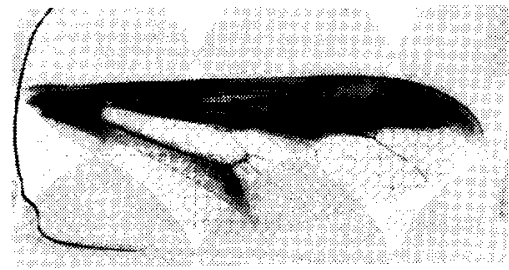

intermedia

41

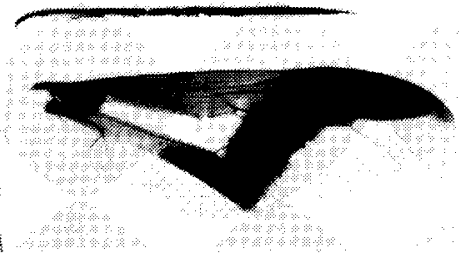

longicornis

43

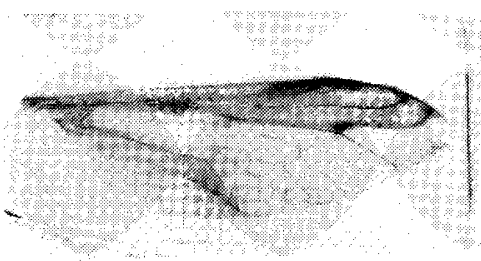

quinquecincta

45

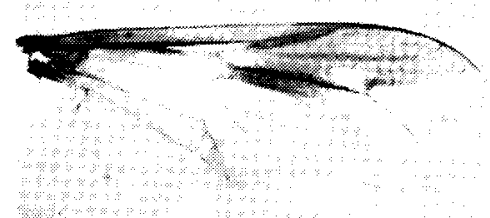

apicalis

47

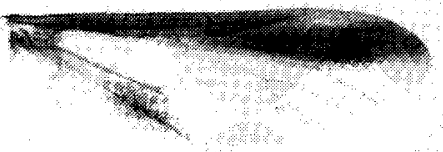

costaricana
40

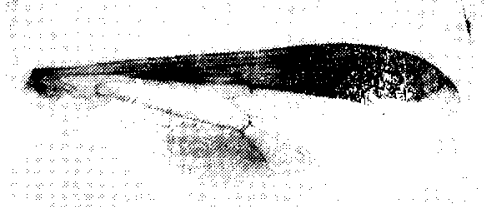

kroeberi

42

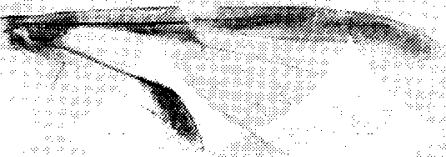

marginalis

44

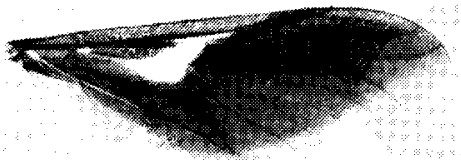

albomarginata

46

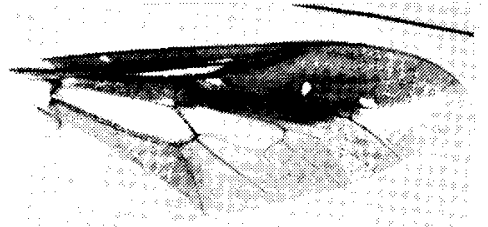

cnephosa

48

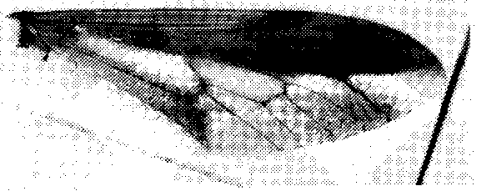

diaphorina

Figuras 39-48: asas. 39, A. intermedia, Lectótipo; 40, A. kroeberi, Holótipo; 41, A. longicornis, fêmea: 42, A. marginalis, Holótipo; 43, A. quinquecincta, Paralectótipo fêmea; 44, $A$. albònarginata, fêmea; 45, $A$ apicalis, fêmea; 46, A. cnephosa, Holótipo; 47, A costaricana, Holcitipo; 48, A. diaphorina, Holótipo. 


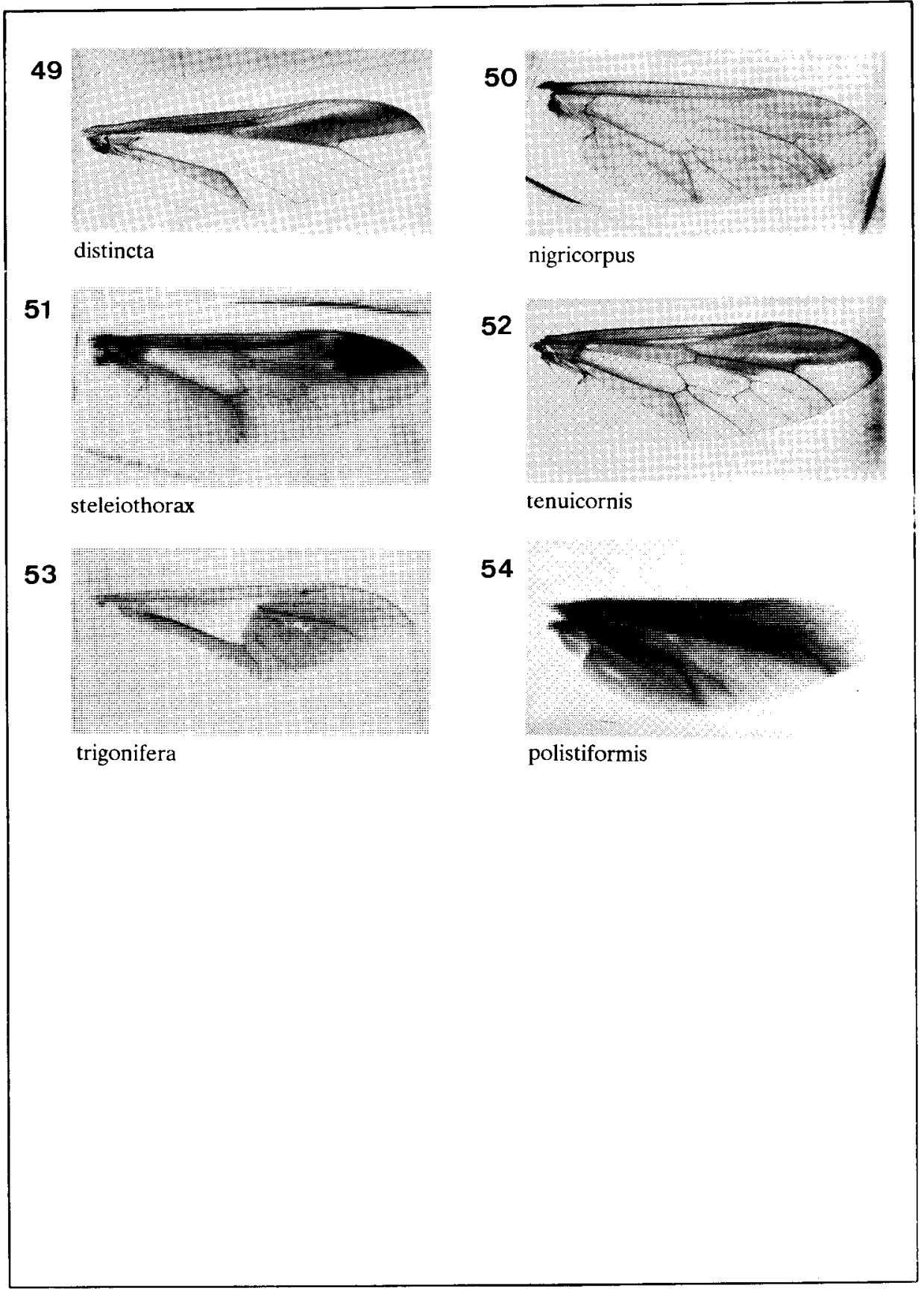

Figuras 49-54: asas. 49, A. distincta, Holótipo; 50, A. nigricorpus, fêmea, 51, A. steleiothurat. Holótipo; 52, A. tenuicomis, fêmea; 53, A. trigonifera, fềmea; 54, A. polistiformis. Holótipo 